University of Louisville

ThinkIR: The University of Louisville's Institutional Repository

Electronic Theses and Dissertations

$5-2018$

\title{
Will-power through physical connectivity.
}

Mia Donata Rocchio

University of Louisville

Follow this and additional works at: https://ir.library.louisville.edu/etd

Part of the Acting Commons

\section{Recommended Citation}

Rocchio, Mia Donata, "Will-power through physical connectivity." (2018). Electronic Theses and Dissertations. Paper 2942.

https://doi.org/10.18297/etd/2942

This Master's Thesis is brought to you for free and open access by ThinkIR: The University of Louisville's Institutional Repository. It has been accepted for inclusion in Electronic Theses and Dissertations by an authorized administrator of ThinkIR: The University of Louisville's Institutional Repository. This title appears here courtesy of the author, who has retained all other copyrights. For more information, please contact thinkir@louisville.edu. 


\title{
WILL-POWER THROUGH PHYSICAL CONNECTIVITY
}

\author{
By
}

Mia Donata Rocchio

B.F.A University of Rhode Island, 2014

\begin{abstract}
A Thesis
Submitted to the Faculty of the in Partial Fulfillment of the Requirements for the Degree of
Master of Fine Arts in Theatre Arts
Department of Theatre Arts University of Louisville Louisville, Kentucky

College of Arts and Sciences of the University of Louisville

May 2018 



\title{
WILL-POWER THROUGH PHYSICAL CONNECTIVITY
}

\author{
By
}

Mia Donata Rocchio

B.F.A University of Rhode Island, 2014

A Thesis Approved on

April 27, 2018

by the following Thesis Committee:

J. Ariadne Calvano, Ph.D.

Rachel Carter, MFA

Diane Pecknold, Ph.D. 


\section{DEDICATION}

This thesis is dedicated to my parents,

Mrs. Cynthia DeVaux Rocchio

and

Mr. Anthony Michael Rocchio

who have unconditionally and selflessly supported me

through every step of my journey. 


\section{ACKNOWLEDGMENTS}

I would like to thank my thesis advisor, Dr. J. Ariadne Calvano. Your dedication to helping and guiding me through this process was constant and generous. I would also like to thank the other members of my committee, Professor Rachel Carter and Dr. Diane Pecknold for their assistance with this project but also for their invaluable contributions to my progress and development during my graduate school career. I want to express the inexpressible gratitude I have for my partner and best friend, Stephen. Your patient love and understanding kept me focused and sane these last 3 years. You define what the word "supportive" means. Many thanks to all of the professors and staff members in the $\mathrm{U}$ of $\mathrm{L}$ Department of Theatre Arts, most notably, Melissa Shepherd, Johnny Jones, Rachel Carter, Janna Segal and Baron Kelly for your direct and indirect contributions to this document and the production discussed within it. Thank you to my family: Anne, Chris, Ben, Ari, David, Jackie, Cal, Antonia, Tina, Giulia and Paul for your presence in my life - my heart is filled with appreciation and love for all of you. Last (but the opposite of least), thank you Megan, for always being there in the perfect moments with an immense amount of encouragement and inspiration-here's to 10 years of being sisters. 


\section{ABSTRACT \\ WILL-POWER THROUGH PHYSICAL CONNECTIVITY \\ Mia Donata Rocchio}

April 4, 2018

This thesis is an examination of my process within the creation of my thesis role, Eurydice in Sarah Ruhl's Eurydice. I begin with the technical skills, such as analysis and dissection of, the text and all of its components (punctuation, alliteration, rhyming, the organization of the lines, etc.), character action and reaction, and historical research into the primary source material for the play, (the Greek myth, Orpheus and Eurydice). These discoveries are framed around a discussion of situating Eurydice within contemporary standards of girlhood. From there, I dive into an examination of the steps I had to take in order to bring myself to this character's personality and given circumstances. My main argument throughout the document is that willpower exists within a strong connection to the body. I walk the reader through my journey of finding physical, internal connection and releasing it outwards, connecting it to external stimuli in order to fuse internal strength with external interaction and visa versa. Physical connection leads to looking at the work I did in regards to physicality and transformation within personalizing my experiences to those of the character. Ultimately, I reflexively consider how willpower and connection allowed the historical and theoretical aspects of my character creation process to be revealed within my performance. 
TABLE OF CONTENTS

ACKNOWLEDGEMENTS ...............................................................

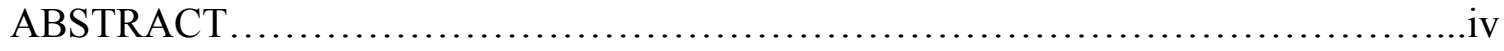

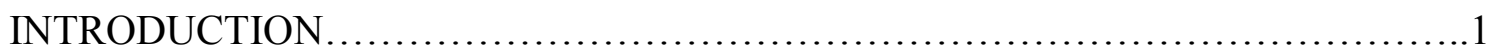

CHAPTER ONE: CONTROL AND DESIRE...................................

CHAPTER TWO: TRUST AND OWNERSHIP ..................................21

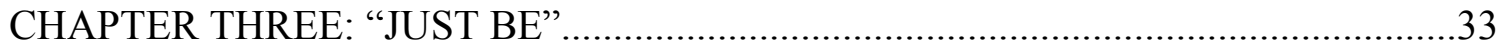

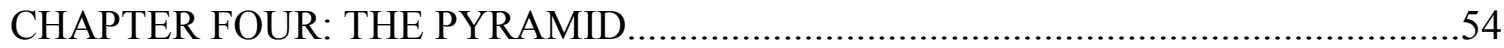

CHAPTER FIVE: POWER OF WILL/STRENGTH OF HEART................................66

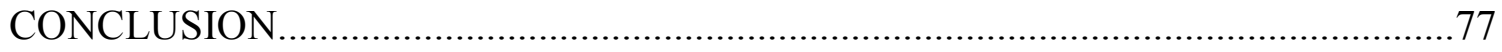

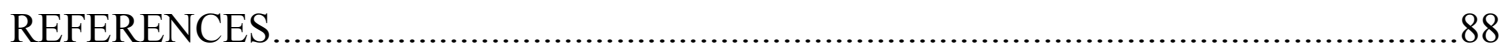

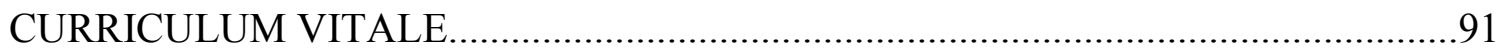




\section{INTRODUCTION}

Over the course of my three years of graduate training, I have been particularly drawn to the ways in which movement and physical choices on stage can propel story. Coming from a background in dance, learning about movement techniques for the actor quickly became my favorite part of acting training. I became fascinated with movement and how expression of the body can, not only deepen the actor's connection to his or her character and the world in which the character exists, but it can also deepen the audience's connection to that character and world. In his book, Visible Thought, The New Psychology of Body Language, Geoffrey Beattie discusses the many ways the body processes and reveals a level of sub-conscious and conscious emotion and desire that surpasses what the brain can produce at any given moment. He says, "When language and nonverbal communication are both used explicitly to communicate $[. .$.$] the language$ channel is virtually ignored" (Beattie 25). I have discovered that activation of a character's desire fuels the depth of connection possible within crafted physicality and maintains a drive, a power of will, throughout a character's journey. The manifested interpersonal, behavioral gestures, hold power and reveal intricate details of the psyche. This becomes the connective tissues that makes the story come alive for the audience.

In the fall semester of my third year of graduate school, I opted to take an independent study. My aim was to further develop skills that relate to storytelling via 
physical movement. Together with my advisor, Dr. J. Ariadne Calvano, we developed a plan that would allow me to dig deeper into the methods with which the human body can be used and manipulated in order to radiate a message to the audience that is just as strong as a verbally communicated message. My intention was to acquire techniques and put them into applicable practice before beginning the rehearsal process for my culminating thesis project. In The University of Louisville (U of L) Performance MFA, each third year graduate is require to take part in a production where they have a significant role, that is referred to as their "thesis role." Over the course of the development process of this production, each candidate is encouraged to document and reflect on their journey so that they have concrete material to then morph into a formalized graduate thesis. At the end of my second year in the program it was decided that my thesis role would be the title character in Sarah Ruhl's, Eurydice, directed by Dr. Calvano. Because Dr. Calvano is the movement professor at $\mathrm{U}$ of $\mathrm{L}$, her vision for the show included a large amount of physical story-telling. Therefore, my desire was to create and produce a movement-driven solo piece, in order to gain and refine this skill set, and to have the project serve as a pre-cursor to my thesis.

The main reason I mention the creation of my solo performance project is because it was within the development and performance of this piece that I stumbled across what have become the central topics of my thesis. These components are, willpower and connection. I found that through willpower and connection, four basic stages of work emerged. First, I established a ground layer of research and allowed that information to sink into my mind and body. From there, I developed a rough sketch of my vision for the story, the physicality that would aid in the communication of the story to the audience, 
and the specific placement of my body in space throughout the story. I then made specific choices for each of those elements and solidified the order and execution of them through repetition. And lastly, after this careful preparation, I allowed the technical details to fade from my mind and released into a sense of imaginative play and freedom as I worked through the journey of my character. These layers then became my model for creation that I applied to Eurydice.

In order to create a specific outlet for the research component and thereby establish the ground layer of my creation process within the development of both my solo piece and Eurydice, I opted to take an elective course in the Women and Gender Studies Department, entitled, “Girls' Cultures.” This class revolved around the study of girlhood and codified systems of the performance of girlhood as taught to girls through mediadriven images and messaging. Involved in Ruhl's play are themes of the journey from girlhood to womanhood, female agency, and gender expression. These particular sociopolitical topics are a big part of my mission as an artist. "Art in action" is not only a large priority for the Department of Theatre Arts at U of L but it is also a significant personal priority and one of the main reasons I chose to attend this program. In constructing any piece of theatre in general, but especially in regard to art that has a socio-political goal, the research serves as the foundation on which to build.

Conversations with Dr. Calvano about the play and all the parts involved in bringing it to life was a big part of my research phase. Within her vision and intention in terms of production choices and the execution of symbolic thematic images for Eurydice, one of the main elements she was passionate about using was string. On page 12 of the play, Eurydice's romantic counterpart, Orpheus, tells her that he loves her. She responds 
with the same sentiment to which he then replies, "How will you remember?" She remarks, "That's easy. I can't help it." But Orpheus is not convinced. He says, "You never know. I'd better tie a string around your finger to remind you." The whole play revolves around the idea of trying to hold on - to memories, to moments, to shared time, and to shared experiences. From my experience and research, cultivating the power to own one's internal truth within a public sphere requires a letting go and an ability to flow through each moment in life, appreciating created memories but also recognizing when something has ended and allowing it to pass rather than trying to cling on.

Water is also a significant motif within this play. It can be used to symbolize the ebb and flow of life and the inability to control the moving tides. Water shows up a few times in the text but most notably as a river that makes one forget everything they once knew. This was referenced by the production's dramaturg, Janna Segal as a specific literary piece of research. Dr. Calvano chose to represent the water and river via yarn; covering the whole stage with hanging string. This not only served as a clever way to remedy the issue of creating water on stage, but it also functioned as a metaphor for the unobtainable nature of memories - the more we try to grasp onto them, the faster they slip away. This relates to the middle layer of creation; putting research, vision, ideas and techniques into practice.

My top layer of creation is letting all the elements of preparation go and releasing into free-play within each moment of telling the story. The journey of creating and performing my solo piece allowed me to discover how willpower and connection can empower my emotions to keep flowing even when a mistake is made on stage, as opposed to attaching thoughts of ridicule and disappointment to fleeting emotions. Upon 
reflection of the rehearsal and performance processes for my solo-devised piece, I hypothesized that this ability to keep the action going and not get discouraged, originated from an internal physical connection between my body and mind in combination with a committed curiosity when faced with external stimulation.

In order to reflect on and synthesize my discoveries within the layers of the Eurydice creation process, as experienced and perceived by me, this paper is organized into chapters that outline each stage of rehearsal. The first chapter is titled "Control and Desire" and focuses on preparation work done prior to the start of rehearsals. It explores the background of the original myth that the play is based on, entitled, Orpheus and Eurydice as well as diving into textual analysis of the play. Through a discussion around the contemporary structure and standards of girlhood, "Control and Desire" positions Eurydice within the frame of identifying as a girl and what that means societally. Chapter two is "Trust and Ownership." I ground this chapter in the context of the beginning stages of table work and dramaturgical exploration within the rehearsal process. I look at the ideas of presence, expression of true desire and ability to confront any and all actions that are a product of following an authentic desire. The third chapter is "Just Be" and in it I go into the physical and mental process necessary in order to confront the self. It is explored through the "on-our-feet" portion of rehearsals and staging. The fourth chapter, "The Pyramid," breaks down Malcolm Gladwell's concept of the performance progression and skill development of what he refers to as, "physical geniuses," within the context of the actor's character building process. I connect this to my approach for creating Eurydice, looking at the final stages of the rehearsal stages. The fifth chapter is a reflection of the 
entire Eurydice process in relation to connection and dealing with the circumstances when inevitable disconnection occurs.

While my aim within my thesis is to dig into why willpower and connection are personally important, I also discuss them within the context of girlhood and female agency. To begin my investigation process, I looked up the Webster's New World definition of both words. This dictionary defines connection as, "A joining or being joined; a coupling; the relation between things that depend on, involve, or follow each other" (309). The provided definition for willpower is, "The power of making a reasoned choice or decision or of controlling one's own actions" (1637). My desire is to understand the full in-application power of the ideas behind these words and define them for myself in a way that allows me to bring them fully into future projects, performances, endeavors and life in general. I will discuss the ways in which society places particular standards on the expression of girls' desires. I will look at how defeating or rather, letting go of, these standards sometimes results in fear, shame, and both internal and external judgement. I will attempt to break down a methodology for simultaneously letting go of the need to achieve a standard while letting go of any and all produced discomfort or judgment from taking a road less traveled. Through an assessment of the skills and tools needed to step into power of will, I will disclose information about my own journey along the path of moving from wanting to obtain approval to trusting my own impulses.

In working through my experience with, and observation of, connection and willpower, I began to realize that the two are connected. However, the specifics of their relationship to one another was somewhat unclear. I inferred that determination and motivation are also a part of the puzzle, but at the beginning of my reflection and analysis 
process they seemed to be strongly intertwined with willpower. Therefore, they were wrapped up in the question, when willpower abandons the body and mind how can it be re-conjured? What happens when the body and mind retreat into fear and self-doubt? Answering these questions led to the crafting of my own definition of willpower. For me, willpower is an energetic force comprised of freedom and bravery, propelling the connected mind and body forward in time and space. This definition is rooted in my experience as a girl and a woman. It has everything to do with reclaiming what female expression looks like and how girls and women can free themselves (via connection to the body) from pressures to perform femininity in codified ways. Grounded within the rehearsal process for and development of, the show and character, Eurydice, by Sarah Ruhl, I conducted interviews and research to understand, critique, and re-evaluate the definitions of willpower and connection, in order to state that willpower is a result of physical connection and the ability to repeatedly return to a connected state. 


\section{CHAPTER ONE: CONTROL AND DESIRE}

Connection requires the ability and desire to openly reach out and make contact

with stimuli existing outside of the internal self. I begin with the idea of releasing control. Releasing the mind's grip on rising emotions depends on making a choice, making the decision to follow and boldly commit to personal desire, even when the outcome of doing so is unknown. Active exploration of something unknown, means following an impulse. There is often hesitation within this process, except in the face of dire circumstances. The truth is the layout and execution of everyday life is, in and of itself, an unknown. We try to manipulate our lives with scheduling, to-do lists and finite organizational measures, in order to avoid the reality that nothing can be planned - that unpredictable events still occur and must be dealt with.

Many people, historically myself included, struggle with this truth. It creates knots in the stomach and an undeniable feeling of self-doubt, rendering a mental hold. Thoughts become glued to the feeling of unease; if nothing is controllable, or certain, or "pin-down-able" how can one trust that tasks will get done, work will be accomplished and life will be fulfilled? Ultimately, this question and others like it, stem from an internal lack of faith in oneself in concert with external factors. Doubt, and/or fear, are 
the very elements that lead to getting mentally trapped and staring at the wall, shutting down to the external world, functioning in a self-monitored, stiff, untrue manner and losing sight of the work at hand — thus producing a lack of results.

In my experience, accessing and following the sensation of desire is the first step to counteract overthinking, avoiding, or giving up entirely. Engaging with one's own wants and pleasures might be looked at as self-indulgent. However, authentic desire, fed by motivated and determined trust in oneself and executed through connection - to the space, the moment, the work, the body - activates many forms of release. Such release includes release from seeing fear, doubt or the unknown as negative, release into acceptance of mistakes and even "failures", and release into embracing potentially overwhelming external stimulation. The idea of grabbing hold of inner desire and embracing the unknown, are themes that I initially began to think about when first encountering the Eurydice text. One of my beginning stages of research as I stepped into the world of this play was extensive study of the original Greek myth, Orpheus and Eurydice.

I began to compare and contrast the information gleaned from all found versions of the myth. The overlapping, identical narrative parts include: Orpheus existing as the god of music and his wife, Eurydice, being a woodland nymph who dies and goes to The Underworld. Out of despair and longing, Orpheus discovers a way to travel to The Underworld to retrieve Eurydice. However, once he arrives, Hades, Lord of The Underworld, informs him that in order to bring Eurydice back to life Orpheus must leave The Underworld trusting the fact that she is following his path without glancing back. If he looks back she will be gone forever. Multiple versions of the story report Eurydice's 
death as something akin to, "one day Eurydice trod on a snake, which bit her foot, and she died" (Rouse, 142). However, Rose, in A Handbook of Greek Mythology, states that the event occurred out of desperation — she was running for her life from Aristaois, the inventor of bee-keeping (112). This is reiterated by Graves in The Greek Myths (112). Hard and Rose state, in The Routledge Companion of Greek Mythology that it is Virgil's retelling that claims the bite was caused from fleeing Aristaois, while Ovid's narrative states that she was frolicking and dancing in the woods after her wedding when the bite occurred $(153 ; 552)$.

The discrepancy in the nature of the events leading up to Eurydice's death, intrigued me. I was specifically drawn in by the difference between the verbs, dancing and running. Both are high energy acts that, in my experience, emit a visceral, guttural power. Also, both described circumstances surrounding the acts of either dancing or running, involve desire, power of will and the idea of choice. In both scenarios she has made a choice to respond to her circumstances. In one rendition, she is fighting for the continuance of her life, while in the other, she is dancing for the celebration of her life to come. Webster's New World Dictionary defines running as, "to go quickly by moving the legs rapidly; to take flight; to escape; to rove or ramble without restraint" (1254). There is a need within these definitions - a cause that prompts the act. The dictionary definition of dancing is, “to move one's feet or body, rhythmically; to leap, skip as from excitement or emotion; to move quickly" (366). Again, there is the sense that a cause prompts the action, but more specifically, there is an internally felt desire caused by an external factor. Both activities suggest a cause and effect; a relationship between the internal and external worlds, brought together through released desire or necessity. There is hunger 
for vitality and prosperity within the words "quickly," "flight," "escape," "move," "leap" and "excitement." There is a sense of fight, a sense of survival, the kind that comes from unyielding commitment of heart. The mental and emotional overlap between running and dancing, brought me deeper into character research and development.

My initial, pre-rehearsal, approach to becoming familiar with Ruhl's story and the character, Eurydice, was to read the play as often as possible. Each time I read it, I would collect information, such as what other characters said about my character, clues found in the structure and design of the text, and significant actions made by Eurydice and how they evolved over the course of the play. Some examples of the later that made a first impression include, her immediate acceptance of Orpheus' seemingly spontaneous proposal (13), her decision to leave her wedding and go with the Interesting Man (20), and her choice of sitting in her suitcase when she is finally given a room in The Underworld (35). I set a goal of simply making observations and asking questions without determining specific choices or making set plans. I wanted to leave space for growth and discovery within the rehearsal process. A key Orpheus quote that served as a central jumping off point for the crafting of Eurydice's inner motor is, "you couldn't wait, you were always one step ahead of the music" (61). This denotes a drive in Eurydice; it sheds light on the possibilities available within the expression of her desire.

A piece of evidence pointing to Eurydice's motivation to run, dance, move and discover, is found within the action and monologue that take place upon her arrival in The Underworld. Ruhl's stage directions read:

An elevator door opens. Inside the elevator, it is raining. Eurydice gets rained on inside the elevator...She looks bewildered...She walks towards the audience and opens her mouth, trying to speak. There is a great humming noise. She closes her 
mouth...She opens her mouth for the second time, attempting to tell her story to the audience. There is a great humming noise...She has a tantrum of despair. (27)

In these first moments of being in The Underworld, Eurydice, as the stage directions suggest, is attempting to deal and interact with her surroundings. She is observing where she has landed and the situation at hand; she is trying to connect to the environment around her in order to figure out what this place is and, perhaps, why she is there.

When she is finally able to speak without creating a "great humming noise," she begins to put the missing pieces together. She starts by recalling the last thing she can remember before she died and works her way up from there, rebuilding and reliving the details of each moment. The lines themselves are written in such a way that suggests a flow of thought and realization. For example, the line, "it was horrible to see his face when I died" (28) is split. It breaks and moves to the next line after the word "face" even though the punctuation and thought behind the line clearly makes it one sentence. The choice to have the thought physically jump in the middle does not occur when Eurydice is talking with or to others-it is a feature of her private expression, her true expression. Also, especially in this moment, the structure of the lines on the page reveal the disjointed nature of the remembered images she is attempting to rebuild in her mind. These elements of her internal life are further noticed within the design of the language:

1 How strange. I don't remember.

2 It was horrible to see his face when

3 I died. His eyes were

4 two black birds

5 and they flew to me.

6 I said no-stay where you are- (28) 
If we look at the number of syllables in each of these lines a rhythm starts to unfold: line 1 has 7 syllables, line $2-9$, line $3-6$, line $4-3$, line $5-5$, and line 6 has 7 syllables. This is a pattern that repeats over the course of this speech. There is a steady ebb and flow; the number of syllables rises and then falls and then rises again, creating a consistent momentum. This directly underscores Eurydice's emotional state and inner desire. Through the process of remembering the events leading up to her death and arrival in The Underworld, she is slowly compiling facts and details about what happened before she stepped out of the elevator. She is eager to remember and continue to discover. For example, as the monologue moves on, she says:

When I got through the cold they made me swim in a river and I forgot his name... They took me a tiny boat. I only just fit inside. I looked at the oars and I wanted to cry. I tried to cry but I just drooled a little.

I'll try now.

She tries to cry and finds that she can't. (29)

The coursing progression of the thoughts mimics the movement of a river, stream or other body of water-it is steady and continuous even though there are dips and turns. She is not dwelling within the emotions that might be coursing through her like, fear, worry, frustration, etc. She is plunging into her memories and her surroundings, attempting to make them tangible. These thoughts are coming back to her as she works her way up to the present moment. This is exemplified when she tries to cry again and still finds she cannot. The conditions of her environment are still the same as when she was dipped in the river and taken into the boat. 
Eurydice's eagerness and ability to move through the moments and emotions of life, rather than getting bogged down within them, is revealed early on in the play. However, her manner of expression, as indicated through the text, is not as raw and true to herself at the beginning of the play as it is by the end. When Eurydice is communicating with the other characters the lines are not broken in the same fashion as what is depicted above, and therefore, the driving energy of the rhythmic score is not as prominent. There are protective layers on top. These layers manifest in many ways throughout the play, besides rhythm of speech, such as through stage directions denoting appearance and physical choices, through implied reactions via punctuation, and through tone of writing and expressed wants and needs within Eurydice's spoken dialogue. For example, the first scene of the play features Orpheus and Eurydice having a romantic day at the beach. The text indicates a demure, lady-like quality to Eurydice. Ruhl's stage directions state, "they wear swimming outfits from the 1950s" (9). We learn that she is proud of her thoughts but reluctant to directly state examples when Orpheus doubts their existence (11) and that she would prefer "[ $[.$.$] another ring —a gold one — to go over the$ string one, you know?" (13). My interpretation of these moments is a display of stereotypical traits of femininity that give a nod to a systematic expression of desire and an adherence to a societal definition of girlhood.

Girls receiving societal messages of how they "should" experience girlhood, is discussed in depth within Sharon Lamb's book, The Secret Lives of Girls: What Good Girls Really Do... Lamb uses the Grimm Brothers fairytales as an example of how, historically, "proper" girl behavior has always been communicated via popular, circulating narratives. In one Grimm tale, entitled, Our Lady's Child, the main character 
is raised by the Virgin Mary. One day, the girl breaks Mary's trust and lies about it. She is then stripped of her voice and banished to earth where a king discovers her and "although she could not speak, she was still so beautiful and charming that he began to love her with all his heart, and it was not long before he married her." The "should," in regard to the behavior of girls that Lamb references is exemplified in the way the main character of this tale is disobedient and therefore is stripped of her voice and rejected, disowned. But she is then accepted and loved deeply by the king because she was "charming": she had no voice and she had "golden hair down to her very feet." These are apparently the two qualifications girls need to be charming and well received-a "proper" way of performing girlhood. Peggy Ornstein also references the Grimm Brothers in her book, Cinderella Ate My Daughter. She uses these fairy tales in order to compare and contrast the girlhood narrative of the nineteenth century with the one projected through the lives of 21 st century pop-stars, such as Miley Cyrus and Lindsey Lohan. Our Lady's Child also provides an example of this "princess narrative," with the assistance of a man, a young, helpless, beautiful girl is rescued and made a queen. Ornstein makes the argument that both trajectories - the Grimm brothers' rags to riches and the Disney Channel citizen to star-communicate that girls can be seen as commodities, and that commodity has to fit the expectations of what it means to be a girl, or suffer the consequences.

I use the example of the Grimm Brothers in contrast with a contemporary example of the same construct in order to show the evolution of perpetuated "correct" ways of performing girlhood. Lamb and Ornstein argue that these behaviors still comprise a standard to which society holds girls. It is my point of view that a 
demonstration of this standard is crafted within Eurydice's actions and appearance at the top of the play. Arguably, it shows how contemporary girls, even smart, courageous, driven and willful ones, can still get stuck within pressures to achieve and project a codified version of desirability.

A big factor relating to and facilitating the manner in which today's American girl believes desirability should be performed is the media's representation and categorization of girls, which essentially breaks down into two labels: The "can-do" girl and the "atrisk" girl. With the help of Anita Harris, feminist scholar Sarah Projansky defines the "can-do girl” as "“confident, resilient, and empowered"” (2) and the "at-risk girl” as someone "who 'lack[s] self-esteem' and/or engages in risky behavior" (2). This harsh binary places an emphasis on individual responsibility for curating the self and leads to a codified performance of girlhood; there are only two boxes within which girls can be placed and one is much more desirable than the other. The protagonist of Our Lady's Child was told that she would not be granted her voice or the continuation of her life until she repented her sins. There is a parallel here with what feminist scholar Sarah Projansky refers to as the "crash-and-burn" girl. In her book, Spectacular Girls, she defines the crash-and-burn girl as "the can-do girl who has it all, but who- through weakness and/or the inability to live with the pressure of celebrity during the process of growing upmakes a mistake and therefore faces a spectacular descent into at-risk status" (4). Thus, in order to achieve and maintain "can-do" status by any means possible, decision-making and actions in general, become internally monitored. There is pressure and a nagging desire to hyper-control actions and reactions - making sure a box is checked each time a word is spoken or an outfit is chosen or a movement is made. The unknown becomes a 
terrifying, horrific concept. Which is problematic because, as addressed earlier, life's unfolding moments and manifesting realities are utterly and completely unknown until they happen. However, in a fierce effort to meet the standards outlined by the model of the "can-do" girl, girls undertake semiotic performances of this standard even when these expressions do not match a given girl's true expression of her identity or of what she wants. Emilie Zazlow deconstructs a similar binary but with different labels. Her version of the "can-do girl" is the "girl-power girl" and she has named her "at-risk" girl, the "girlin-crisis girl." Of the girl-power girl, she makes the argument that they are driven by consumer choices and told that happiness, confidence and strength are found within the ability to consume products:

Neoliberalism raises individuals as pinnacles of civilization [...] In this scenario, power emerges from the choice-making of individuals rather than from structural supports or systemic change and the emphasis on personal responsibility leads to increasing attempts at self-improvement and self-monitoring. (8)

Eurydice's brief mention of wanting a material possession at the top of the play is reminiscent of what Zazlow is describing in the above passage - self-worth based on personal appearance and presentation. The argument can be made that she gets swept up in a need to fulfill a societal expectation. I believe the action of wanting the gold ring to be contrary to her authentic self.

The real nature of her desires is revealed in the second half of the play when Eurydice reconnects with her father. She fully indulges in and broadcasts her love for words, language, knowledge and ideas, in a way the audience does not see in the First Movement. In one scene, when she is getting to know her father again, he teaches her words and what they mean. She then takes these definitions and rewrites them: 
"peripatetic: A learned fruit, wandering through the snow" (41). She taps into a place of full and true self-expression that was perhaps forgotten. Her language becomes more poetic and filled with metaphor and vibrant imagery: "[...] the moon is always rising above your house and houses of your neighbors look dull and lacking in moonlight" (51). However, at the same time, she demonstrates almost child-like, curiosity-driven explorations and reactions to the world. For example, when a book arrives for her in The Underworld, it is the strangest object to Eurydice. She stands on it, talks to it, tries to interact with it, throws a tantrum and decides to hate it (44) — following and committing to multiple, fully expressed emotions as she relates to the world around her. Then, later, when Orpheus arrives to whisk her back to the world of the living, she, at first, dutifully follows behind him but then abruptly changes her mind, decides to catch up to him, and whispers his name in his ear (60). The world precedes to "fall away" (61) and she returns to The Underworld. Throughout the entirety of the play, there is an impulsivity to her actions. In the beginning it is slightly hidden and by the end it is a bit unbalanced the other way; the emphasis of youthful immediacy simply shifts in weight.

When first approaching the text, Eurydice's journey throughout the play was a bit unclear to me. At first glance, it seems to be in tandem with developing the bravery to become more connected to herself and her authentic desire-driven impulses. Her decision making across the board becomes rash and she gives into her every impulse — exhibiting essentially the same level of commitment to, not just expression-based impulses but also, emotion triggered impulses. Therefore, interpreting the development of just her agency, or sense of self or confidence, was not the most accurate way to assess her evolution. While these things developed and became more outwardly radiated so did her fear and 
naturally built-in protective, physical reactions to uncomfortable, or even what her body may deem, unsafe situations. It seems she journeys to an earlier place in her development in order to truly re-connect with her natural sensibilities and sensory reactions. When free expression is allowed the body and the mind work together, producing decisions that are based in the authentic desires of the individual. If there comes a point when decisions start to be based in a comparison of the self to others, or in an attempt to meet a standard, the development of naturally experienced and fully expressed wants and needs become controlled and measured.

Eurydice's journey allows her to regain a strong sense of play and honest desire to uncover the universe and all it holds, unabashedly launching into revelation through trial and error:

What is this?

She opens it. She doesn't understand it.

She throws the book on the ground...

What do you DO?!

Say something?

I hate you!

She stands on the book, trying to read it. (44)

In the above scene, Eurydice investigates a curious object that falls from the sky. In order to examine the object, she returns to a place of doing what feels good, acting out of pure desire. There seems to be a strong connection between her mind and body. The thoughts come, they trigger a physical reaction which evokes a feeling and the feeling is not judged by the brain but simply acted upon as the action moves forward. There is no hesitation or second guessing. There is no apologizing for her actions. This seems to harken to a time, an age, before she would have known the specifics in terms of everyday 
skills, before she monitored emotion-based reactions or fell into gendered constructs influencing girls and women to apologize and feel guilty for emotional expression. In Eurydice's case, expressing purely emotion-filled reactions led me to the thought that perhaps here, in The Underworld, she does not think to compare herself to others or is not aware of specific social standards. Perhaps the sense of abandon is because being with her father again returns her to a younger state of mind; or perhaps it is because here, in The Underworld, she does not feel as though she needs to be in touch with such customs.

Either way, stepping into the character of Eurydice and accomplishing an authentic portrayal of her raw energy for life required that I take a time traveling journey. In order to find the discovered rhythm that makes Eurydice tick — her ability to flow through situations, actions and reactions - I needed to examine my own methods of performing girlhood and become aware of components within this performativity that stem from an outside influence rather than my authentic self. This required going back to a time before my actions and reactions became stinted due to hyper-self-awareness and a desperate need to perform socially in a specific manner. Giving my all to the development of this role, mandated that I strip the layers of self-soothing, physical and mental habits I have cultivated, and I would argue that many women cultivate, in order to keep my heart a safe distance away from potentially harmful external stimuli. Suddenly, owning my space was a part of my job description. 


\section{CHAPTER TWO: TRUST AND OWNERSHIP}

Claiming my actions within the space around me in any given moment, being proud of them, and fully accepting any and all experienced embarrassment or received judgement was the first step to opening up to my environment and to finding a deeper trust of myself. For me, an ability to trust the self means belief in, respect for and admiration of one's existence and presence within time, space and/or a given situation. In her book, Letters to a Young Artist, Anna Deavere Smith defines presence as the ability to "[...] hold your own space, control the space around you, and sometimes welcome others into it" (12). Based on this definition, some of the immediate factors that impede my ability to take control of my presence are, self-doubt, a lack of self-worth and reluctance to confront inner truths, such as amount of knowledge, experience, personal beliefs, moral codes, personal daily lifestyle choices and habits.

Taking responsibility for one's space means taking responsibility for all parts of oneself. When following desire-based actions, the process of owning the results can be blocked by the temptation to get caught up in comparisons or societal standards when elements of identity come up that feel vulnerable. This process is two-fold. On the one hand, the impulse to compare or self-monitor could be because the expressed action is a less available part of the self and so feels initially scary to reveal, or, it could come from a 
genuine place of doubt in regard to the affect one's actions have on others. There could also be a sense of concern as to the credibility of the base of knowledge within which the actions are grounded. I have found that in both scenarios the root of the problem is fear. The best way to combat fear, I have discovered, is to enthusiastically embrace it. There is no other option but to grab a hold of it, claim it, roll around it, and look it square in the face and say, yes, here you are, come on, we're going to work together-I am going to go through you, instead of running away from you. Of course, this mentality, can ultimately lead to making mistakes, to saying something regretful or even hurtful or allowing actions to become impulsive in a way that is careless and could lead to mental or physical injury. However, full transparency then becomes key. Smith goes on to say, "presence will probably, in the near future, be based on absolute authenticity. Whoever can achieve that in a world of brands, and seductions, and false promises, and addictions to false loves, will be truly charismatic [...] Dare to open your heart to the good and bad around you" (20). And I would add, dare to open your heart to the good and bad inside of you. A courageous, open heart can face any truth with ownership, accountability and determination to move forward.

Bravely embracing my faults and fears is where my journey really started to burst open within the Eurydice process. The beginning rehearsals involved reading the script aloud, working as a group to generate images for each scene. Then bringing these images and other table work ideas about relationships, character development, and story arch into physical explorations within the space. One of the ensemble building exercises we did involved finding a partner and following them as they walked. In this exercise, the first step is to just observe how your partner is moving. What part of the body leads their 
momentum through space? What is their tempo? What are their limbs doing? Once all the details are taken in, the walk is then embodied by the observer. For this exercise, I worked with my partner, the actor portraying Eurydice's husband in the show, Orpheus. As I wrote in my rehearsal journal after the exercise, "my partner's movement involved freedom and flow in his shoulders as well as in his head and neck. These two parts of the body operate with smooth, flowing movement that is independent from each other but still connected and whole." Taking on this physicality within myself proved challenging because I found that it involved not just physical freedom and looseness, but also, mental freedom.

The physical hurdle with embodying my partner's walk was allowing my head and neck to operate independently from my shoulders. Simply giving my shoulders permission to move at all, was the first challenge. Finding movement in the shoulders automatically triggered engagement of the head and neck. This resulted in a bouncy, swing effect throughout the entire body, rather than a liquid and smooth locomotion. Separating the head, neck and the shoulders, giving them each their own life, mandated a mental and emotional freedom that immediately hit my body as uncomfortable and perhaps unsafe as a great deal of anxiety was released. Allowing the upper body separate freedom felt very alien to me. It required me to take up space in a way that felt inappropriate, brazen and invasive to the others around me. The later idea about invading others' personal space is definitely the factor that holds me back the most in terms of embracing the uncontrollable nature of the moment and releasing into my impulses. In reference to my discussion from the first chapter about standards of girlhood, the way that I perform girlhood and/or womanhood has proven inhibitive to giving myself 
permission to take up space in what feels like a bold and unapologetic manner. There is a very clear line that my body and mind hold me back from crossing; this line is marked by my perception of the comfortability of others around me. In the moment of the walking exercise, I felt as though this new way of walking was requiring me to own my space, to "dare to open my heart" for all to see and for me to see all. It was this moment that confirmed the kind of adventure on which I was embarking. The adventure was not just about me confronting my inner truths, but also largely about confronting whatever energies, feelings, or reactions I receive or perceive to receive from the world around me.

The experience of becoming receptive to the external world with a sense of discovery, rather than emotional subjectivity, is explored in Jaques Lecoq's idea and physical exploration of the neutral mask. I had the opportunity to work with this technique in the summer of 2017 at the Pig Iron School and Theatre in Philadelphia, PA. Of the neutral mask, Lecoq, in his book, The Moving Body, describes, "Essentially, the neutral mask opens up the actor to the space around him. It puts him in a state of discovery, of openness, of freedom to receive. It allows him to watch, to hear, to feel, to touch elementary things with the freshness of beginnings" (587). There is an objectivity within discovery in this place of neutrality. Lecoq references this objectivity when he talks about "[...] neutrality prior to action" (569). In doing the work, and later when applying the work to Eurydice, I experienced this moment before action as a sensation of breath in the whole body - the stimulus of the space has been received and there is a moment of acceptance and then immediate connection via movement and the want to discover. The actor's will to move forward is triggered by investment in the surrounding 
environment and discovered landscapes and imagery. There is curiosity but do not take up residency there. There is a sense of urgency—what's next?

For a long time, I deemed curiosity as the key to unveiling the world's most thrilling secrets. However, I discovered that at times, for me, the act of dwelling in the romantic notion of curiosity can result in disconnection from the external world. I have experienced it as a dull, internally stuck feeling. When confronted with the neutral mask, I was suddenly asked to move through curiosity; to activate curiosity in a way in which I was not overly familiar. I was told to use it as a door and keep going, keep doing. If I needed another door, it would be there for me. Within the context of Eurydice, I realized that the doorway is acceptance. For example, in the moment at the end of the play when Eurydice returns to The Underworld, she walks in to find that her string room is dismantled and Her Father is lying on the ground (66). Engagement in the unfolding moments of the external world is the key to discovering the why's and how's of the reality she walks back into. At first, I experienced a sense of nervousness, fearing I would slip into anticipating the reveal of what has happened to Her Father. However, in order to claim the space and stay invested in the real time of the story, vulnerability and fear must be acted upon. The neutral mask demands alertness and activation. These are two qualities that make up Anna Deavere Smith's description of presence. I would say to myself, "yes, you are being watched; yes, there may be judgements and perceptions being made about you, in this very moment; and yes, there is a chance that you might anticipate the events." The moment at hand is received and whatever is delivered, either externally or internally, is accepted "with no inner conflict" (Lecoq, 569). Trust of the self comes from forward momentum, not attempts to go backwards. 
Stephen Wangh discusses trust of self within arising physical and mental impulses, in his book, An Acrobat of the Heart. In it, Wangh leads the reader on a journey through a particular portion of Jerzy Grotowski's methodology. At NYU in the 1960s, Wangh studied with both Grotowski and Ryszard Cieslak, a performer who worked closely with Grotowski. When introducing physical impulsivity and how to move it around and through the body, he talks his reader through the difference between following an impulse, while consciously observing where it's going and losing all awareness of self within an impulse. Of this balancing act he says, "having an impulse doesn't mean being out of control. It just means allowing energy to flow through your body. How you use that energy is something else" (35). He goes on to discuss how "[...] an impulse can be redirected, turned, transformed and still be an impulse" (35). He explains how it is not necessary to follow the impulse in your arm by throwing a chair. This impulse can simply be redirected into slow motion lifting of the chair or perhaps even a scream (34). It is necessary for there "[...] to be a negotiation", especially when the work starts to involve others, even if this negotiation is as simple as a one second exchange of a look (35). Wangh's introduction of the term "negotiation" is useful in connection with the previously discussed idea of monitoring one's actions and impulses. A quick but tangible negotiation solves the problem of toxic analysis that leads to defining self-worth through consumerism and prescribed behaviors. But at the same time, trust of the self is still engaged. Allowing the impulse to manifest in some way gives it a voice and therefore validates its existence. However, unspoken negotiations require nuanced communication skills, physical vulnerability and emotional maturity. 
The fall semester of my third year involved an independent study, in which I developed a solo performance. Part of the curriculum within this class involved an introduction to aspects of Wangh and Grotowski's pedagogy. Through my limited experience with some of their physical training exercises, I have trained my spirit and enhanced my motivation in order to be able to view "a split second [...]" as, "[...] plenty of time to ask a question and receive and answer" (Wangh, 35). The trick is to fully embrace the answer, and whatever it is, reconnect to the moment and keep moving.

In the second week of Eurydice rehearsals, we moved into extensive physical exploration. This aided the process of enhancing my awareness and my characters' impulses, relationships, and actions. We began to investigate the text through ensemble generated images. Once an image list was compiled we moved into physical explorations. Plastique is Grotowski's term for isolated movements of different body parts in order to stimulate memory and conjure imaginary, visual entities into the playing space. The term corporel identifies movements that have the same aim in regard to generating images and feeding impulses, but involve more than one body part at a time and aim at spinal activation. A large majority of Dr. Calvano's training is in a Grotowski-based system. Since the cast members had all taken classes with her, we all had a basic understanding of her language and exploration styles. Therefore, it was possible for these exercises to be seamlessly brought into the rehearsal space at the beginning discovery period. Because this work involves balancing the internal and the external, the body was used to expand awareness of time and space and to communicate. Ground work was laid for relationship building, physical and gestural choices, action through use of the body, and discovery of 
meaning behind the text in terms of how the text stirs one's emotional, physical and mental life.

A part of Jerzy Grotowski's actor training was the idea that "[...] it must be as easy for you to enter the stage walking on your hands as on your feet...This means, it should be as difficult for the actor to enter the stage on his feet as on his hands" (as qtd. in Wangh, 43). Wangh goes on to unpack this sentiment in his own words: "every step we take with our feet and legs should be as meaningful, as justified, as conscious as if we were walking on our hands" (43). In order to get more in touch with inner physical connectedness and unified movement, it is crucial to understand how the body moves as one entity within all activities. Without use and awareness of the whole body, physical impulses — triggered by external or internal stimuli — will be missed, causing expression of desire and need to be less alive than when the whole body is working to communicate and receive.

When physical exploration was introduced in the rehearsal room, it was explained that the space was being broken into four corners. We would read a scene and then everyone would contribute to building a list of images that came up while the text was being read. We would then assign each corner of the room a corresponding action or phrase for a given image. The actors who were in the scene would then enter the space. The lines would be read and the actors would move about the space listening to the lines, exploring impulses that arose in the body while moving in and out of the actionappointed boxes, depending on which image we connected with in the moment. The actors had the option of opening themselves up to/interacting with the other actors in the space. We were working the scene when Eurydice expresses her hatred of parties while 
taking a break from "the biggest party of all" (17): her wedding. I was in the box that had been given the action "to entice/to radiate." On the line, "the mothers all dress up trying to look like young women" (17), I suddenly had a significant sensation in my chest/heart area. I started exploring a corporel in which I was seated with my legs out in front of me and my arms reaching up and opening out, towards the sky. It was this position and moment where I first felt completely connected to Eurydice's mental and emotional energy.

As my hands were reaching towards the sky and my heart was opening, I found antithesis within the sentiment of the line. Eurydice's action at this moment within the trajectory of the play is to reach up towards married life and motherhood. However, her desire is to reconnect with a missing piece inside of her-i.e. her father... although she might not be fully aware of that at this moment. The latter discovery came like a rush into my body when the next line was read: "but a wedding is for a father and a daughter. They stop being married to each other on that day" (17).

Before each scene was explored in the space, the cast would read the scene aloud and then brainstorm images that arose for us as the words were being read. The image that had originally inspired the action for that particular corner was, "a pillow full of razors." When this image was first said after the scene was read, I remember thinking that I couldn't connect to it; I was slightly taken aback by it and not sure I understood the emotion associated with it or the metaphorical meaning. However, when I was in that box and heard the line about fathers and daughters, I immediately realized why my impulses had taken me to that box. Through marriage, Eurydice was hoping to fill a part of her that was stolen when her father passed away. However, reaching for that resulted in a pillow 
full of razors - a deceiving image of comfort and fulfillment. In this moment of physical discovery, I successfully passed through the door of initial curiosity, allowing my body to take over while my brain simply observed.

Because I was so connected to my body in the particular moment of that corporel exploration, I experienced free flowing emotion in the body. Wangh says, "acting requires having emotions - not manufacturing emotions, but not blocking them either" (32). Often, within the context of a scene, especially when I know it calls for a strong emotional display or reaction, I fall into the trap of thinking ahead to that moment, rather than discovering it in the moment of the story development and via physical impulse. It can feel a bit reckless to dive fully into the unfolding action and lose sight of what's to come. It can feel irresponsible in two large ways: first, it feels as though lines, blocking, and other technical components will fly out of my head and second, if I am not safeguarding my emotional reactions something crazy could happen that might be uncomfortable for not just me but others around me. On stage, and I would argue also in life, allowing oneself to let out emotion is a big risk. Wangh puts it best when he says, “[...] safety without risk can be boring, and risk without safety is self-defeating” (36). I interpret this as, in order for discoveries to surprise, and vivid images to electrify, planning must be sacrificed. However, a strictly caution-less lifestyle leads to danger and self-indulgent acting. I have found that imagination is the entrance into truthful discovery and an honest opening of the heart to experience the emotions within each unfurling moment.

In his book, An Actor's Task: Engaging the Senses, Baron Kelly discusses the importance of the imagination within an actor's work: "the actor must be conditioned to 
viscerally feel an action, and that will enable him or her to create an imaginary reality" (xi). Action then becomes the key. What is the character doing? Why are they doing it? Is it because they want something? What is it that they want? How are they trying to get it? The last question then circles back around to the first question... what is the character doing? Staying within the cycle that is this questioning and seeking process allows the actor's imagination to stay constantly engaged and active within motivating actions and therefore generating full commitment to and belief in the imaginary circumstances of the character. In an interview with Professor Johnny Jones, the question was asked, "what does connection mean to you and how do you use it in your life, your work and your art. He talked about how, for him, in regard to his interest in the interdisciplinary overlap between anthropology, performance studies and art, "connecting reveals the possibilities available." Jones said, "connection is an entrance point; a 'third space' that leads to making discoveries." Therefore, the actor staying connected to his/her imagination, places trust in physical, emotional and mental impulses, making way for them to take over and guide action.

Trust takes courage, courage takes willingness to risk and risk takes acceptance of possible embarrassment, judgement, and shame. However, if acting on desire results in shame, the mere fact that it was a product of impulsive desire, means it was connected to a primal, physical, incredibly human sensation and want. In my experience, it is useful to follow the desire even though there is a possibility for the action to be socially inappropriate or misinformed or rash. Desire fed action is an authentic expression of self and identity, thus aiding in the process of self-discovery. Children do this all the time. They follow primal impulses that originate in the body and sometimes it leads them to 
doing things like knocking over a plate of cookies, biting their sibling, or taking all their clothes off in the middle of the store. The need for play in order to discover life and what it means and how it works does not magically disappear on the eighteenth year of being a human. So why do the rules of how we experiment with life and exploration change so drastically? Learning is the process of acting from desire, making a mistake, being aware of how and why it was a mistake, and acting from desire again in order to find a solution by moving forward. Learning is owning desire and owning action and this is discovered through trust of play. 


\section{CHAPTER THREE: "JUST BE"}

Giving permission to the body for impulsive play is an action of release, but it takes directed energy of thought. An exercise that has come up repeatedly in my graduate training that has become very useful for tapping into a raw sense of connection and truth while staying present in the moment is called, "just be." I have experimented with this exercise many times and with a few approaches that have stemmed from different sources. It is through combining and blending these different versions, specifically the ideologies behind them, that I found a way of mentally and physically approaching this exercise that best works for me. The basic premise is to stand on stage, in front of the audience or class, and just be. That is to say, it is not a performance. The participant is not up there with the intention of performing; nor are they to block any sensations or feelings that arise. The participant simply receives the audience, the stimuli he or she is confronted with, and allows the body to respond through releasing natural impulses. The only objective then becomes to allow the breath to flow freely and to not put any emotion or coloring on top of the response nor to impede any impulses. As referenced, there are many acting techniques that encompass the philosophy behind the "just be" exercise. 
For me, the principals of this exploration boil down to connected listening and responding. In his book, Sanford Meisner on Acting, Meisner walks the reader through a scene in one of his classes where he engages the students in the act of doing by means of listening. He gives the instruction, "Just for yourselves, listen to the number of cars that you hear outside. Do that" (17). After they close their eyes and tap into the soundscape around them, Meisner asks them how many cars they heard and if they listened as themselves or if they were playing some character. One students says, “[...] I was listening as a student" (17), to which Meisner responds, "that's a character [...] [at any point] Were you listening as Anna?" (17). She tells him that she was by the end and Meisner then proves his point: "so part of your acting was legitimate and two-thirds of it was pretending" (17). Much of Meisner's philosophy revolves around the idea that the act of "playing" a character is a false action and therefore will always come across as untrue. The idea of "just be" allows the actor to release any need to become something else. Through just being, the actor simply brings themselves, their actions, and responses, to the circumstances at hand. The idea of characterization is layered on later. Through Meisner's lens, and at the root of "just being," acting in truth means fulfilling the "reality of doing” (17). Meisner describes this as, "if you do something, you really do it!” (17). For Meisner, the reality of doing begins with listening, with receiving.

Truthful listening, for me, was the first of a series of layers within the Eurydice rehearsal process that, from my perspective of the experience, was crafted to gradually build into truthful expression and consequently, truthful action. This structure allowed a seamless transition between working in an abstract, movement-based manner to moving the text onto its feet in a more traditional sense. The preliminary physical exploration 
proved to me that playing the role of Eurydice was going to require a willingness and ability for vulnerable expression. As exemplified in the seated corporel where I was reaching towards the sky with my arms, achieving truthful portrayal is possible when the body and mind work together to access emotion.

My relationship with emotional availability on stage has always been a bit tenuous. There have been moments in my life where emotion comes very easily. So easily in fact, that I tended to stay in whatever emotional place I had accessed for the entire time of the production, on stage and off. Needless to say, my personal life then became a bit infected with the world and life of my characters. Therefore, I constructed a barrier and now have the opposite problem — my real life is unable to seep into my acting. When faced with the necessity of bringing myself to the circumstances of the character, I was saddled with the task of restructuring the barrier, allowing my life to come into my work but attempting to leave my work out of my life. I have discovered that the tool needed to create such a portal is listening.

In previous experiences with practicing the exercise "just be," especially within the layer of active listening, I have found myself wrestling with anticipation. In order to open the window and allow life experiences to inform the stories I tell onstage, full commitment to one moment at a time becomes crucial. This requires self-trust and ownership of whatever action comes out of the body. There is a discomfort involved here. I am more comfortable when I am in full control of how my responses to stimuli will come out of my body. That way, I can properly assess how someone is going to receive me and then customize my actions to be as pleasing as possible to the given human(s) I am facing. Again, this goes back to the feeling of dread associated with the possibility of 
shame evoked from making a misstep, expressing something via following a physical impulse that is "wrong" based on societal expectations, as Lamb spoke about. Therefore, the first hurdle to address when attempting any amount of transparency and raw-hearted expression is to launch myself into discomfort, to embrace it. It is, however, the power of discomfort that can tear down any and all courageous momentum. While I recognize, intellectually, that discomfort is the pressure through which it is necessary to traverse through order to find strength of spirit, grace and ultimately, growth; it is sometimes impossible to feel these worthy rewards within the heat of the moment.

Practicing "just be" within a classroom environment is drastically different than bringing those tools into the context of rehearsal and performance. I did "just be" for the first time in my beginning year of grad school. In the controlled environment of a classroom, we were first instructed to just stand in front of the audience; in a similar way as laid out in my original description of the exercise. The next layer, was to recreate a moment in our personal daily routines, such as morning tasks. In both situations, I remember an intense naked feeling that washed over me for just a few moments until I was able to escape and sit back down, returning to my role as a student. However, when I attempted to apply "just be" each night in rehearsal when I stepped into playing Eurydice and interacted with her circumstances, I experienced a significantly heightened sensory awareness that made receiving external stimuli feel like a lightning bolt to the system, and this time I did not have the privilege of hiding in the performativity of being a student. Existing for an extended period of time in this physical and mental place of openness, amplified my reception, and hyper-sensitized my body. 
While inviting emotions is one of the goals of acting at times, I felt myself slipping back into a place where emotion only flowed hard and fast, resulting in a leak into my outside life. At first this seemed uncontrollable. I am a sensitive person who receives stimulus in a powerful manner, hence my original creation of the barrier. But then I started to understand that ultimately the objective is to feel the emotions fully but also to allow them to flow through the body, change, and drift away. Betsy Polatin speaks to this idea in her book, The Actor's Secret, when she says, "allow your feelings to move through you. Do not attach yourself to them" (Polatin, 159). However, when attachment does happen, what are the tools available to reconnect and move on? In attempting to answer this question, and find flow and connection within my experience of emotions, I have found it is necessary to face all arising feelings. This requires active re-direction of impulses to avoid or suppress emotion. Frequently, in my experience, re-directing avoidance or suppression requires confronting fear.

In rehearsal, I discovered how the energy received from internal stimuli can be directly placed into and activated through external stimuli, thereby overriding fear. This process involves balancing awareness between the internal and the external worlds while driving through the unknown. I use the verb "driving" carefully. As Webster's New World Dictionary states, "to drive" can mean an overexertion of effort: "to force to go; urge onward; push forward" (436). However, it can also mean, "to cause to go through $[\ldots]$ to impel or propel as motive power" (436). Please note, my intention with this word is to speak to the later definition. I aim to refer to an energy of thought directed into the mind and body, encouraging forward momentum, while objectively watching the outcome of events; as if one were driving a car through an unknown landscape, 
navigating the terrain while simultaneously wanting to soak in the sites as much as possible.

Energizing action through full appreciation of the moment at hand, seems to be the antidote to anxious anticipation. I remember always having this thought in Eurydice's Underworld arrival after having discovered the train. Eurydice says, "oh! I'm waiting for someone to meet me, I think" (29). This was a moment where, at first, I fell into the trap of anticipating the next event of Her Father ${ }^{1}$ announcing his presence. However, eventually, I was able to fully invest in the moment by soaking in the environment around me: the colors, the sounds, and the other cast members on stage. Taking in the realities of my surroundings not only released my imagination into a place of freedom where my brain started producing other environmental factors, such as smell and the texture of the ground under my feet. But, when the only desired object is interaction with the present moment the proceeding events come as a true surprise.

Eurydice's Underworld arrival proved to be where the majority of my discoveries about confronting and releasing the sensation of anticipation came into play. When the scene begins, Eurydice has just died by falling down the high, narrow stairwell in the Interesting Man's apartment. In our version, she was carried off the stage by the stones and then returned through the elevator. Coming out of the elevator was the first time she saw The Underworld. It was in finding this moment of discovery, exploration and awe, that I first understood what it meant to go through the discomfort of not planning a reaction, and instead exhaling through nervous anticipation in order to be truly surprised

\footnotetext{
${ }^{1}$ The name Ruhl has given this character.
} 
by my surroundings and the developing events. Thus, I began to develop a deeper understanding and personal methodology for this process.

Refining the process of releasing into discovery was aided through my practice of the Alexander Technique. Polatin's book is the text used in Professor Rachel Carter's Alexander Technique classes. I have worked from this book for the past four semesters of my training. Polatin is a professor at Boston University and has spent the majority of her life developing training for the actor that is based in the Alexander Technique (AT). The pedagogy revealed in her book, features a mesh of AT with her study of trauma and physical holding in the body from a psychological perspective. The basis of AT is becoming acquainted with the body in a way that allows an awareness of personal physical habits and learned behaviors that have developed over the course of life experiences. AT teaches the idea of "non-doing, doing" in order to "un-do" in the musculature of the body and return to a place of productive "use."

Defining use is probably most productive through an explanation of misuse. A subsequent text taught by Professor Carter, that also outlines portions of AT, is The Voice Book, by Michael McCallion. McCallion discusses misuse through the comparison of a football fan and a baby. He says, "Babies can scream for hours and not hurt themselves or lose their voices. On the other hand, a visit to a football match will often leave a burly man with a worn-out laryngitic croak of a voice" (3). He goes on to explain this difference in vocal efficiency by stating,

$[\ldots]$ the baby[...]uses its body in the way it was designed to be used[...]The football fan's vocal mechanism is no less efficiently designed than the baby's, and he should be able to support his home team for a couple of hours without losing his voice. If he can't it's because he is doing something to interfere with the 
functioning of his voice. (4)

Essentially, misuse develops from disconnection within the body due to learned behaviors and mannerisms as a response to external stimuli.

Polatin expands this same idea by describing the general idea of good use; "good use allows us to use ourselves in empowering ways that open and expand channels of expression, so that each movement and gesture becomes a conscious manifestation of full spirit, mind, and body" (17). She goes on to explain that human reaction to stimulus manifests in multiple ways that can impede the process of the whole body working as one and therefore limit the range of expression available. In order to address and redirect the body and mind into a place of connected release, Polatin has created an exercise in which attention is paid to curiosity of experienced discomfort (86). She calls this process "selfregulation" and describes it as bringing "your awareness to a situation" and asking the question, "are you sure you want to be holding that muscle?" (86). She explains that, with awareness "[...] the body will often regulate itself back to homeostasis, or equilibrium, when you are able to 'be with' the discomfort" (86). I have found that this process is the same no matter the kind of discomfort one is facing. Sensations of discomfort can manifest physically, mentally, and/or emotionally. This process of "being-with," as Polatin has named it, allows the mind to accept the sensation so the body can move through it faster. For me, this exercise and philosophy has served as an active method for accessing and applying the ideas of "just being" and Meisner's reality of doing.

As I slowly began to apply this mode of thinking within my scene work, I began to understand how acknowledgment of personal sensation can allow the actor a closer connection to the action of the character. For example, over the process of my 
development with Eurydice's monologue at the beginning of "Eurydice's Underworld arrival," I began to understand that she's seeing and reliving the memory of dying. Entering into memory produced the action of "to paint." This action immediately connected me to the reality of doing. I can remember, at first, Mia the actor, experiencing sensations of feeling very watched in this moment and not being able to shed that feeling, resulting in only $50 \%$ commitment to the character and the character's actions in the moment. The other $50 \%$ of my concentration was going into thought and anxiety, thus I over-planned my actions and predicted my discoveries. However, once I was able to label and admit to these feelings, I found a deeper connection to the breath and an almost instant activation of Eurydice's objectives.

My journal entries from this period of discovery talk about how, in order to tighten the thoughts, take the space out in between the lines and act on the lines instead of before and after them, breath needs to be free and active in my whole body. The key is to place/channel/redirect the energy I feel for the want to think and plan into my breath. Redirecting the impulse to plan into my breath brought me deep within the intercostal muscles in between the front and back ribs. I would feel anxiety in my chest and through exhaling I would be able to send it out through the musculature of the torso. However, I frequently ran into problems here because my muscles would tighten and tense, prohibiting the breath from moving through all the layers. Successfully enacting this rechanneling required that I first develop the ability to quiet and organize my anxious, selfconsciousness, so that my muscles would relax and release.

Polatin's "being-with" exercise is what helps me to re-organize and settle my thoughts so that I can listen and receive external stimuli with clarity of mind. However, I 
cannot successfully execute "being-with" when my system is overwhelmed with sensations of judgment, monitoring, and panic. There is a first step involved. Polatin describes a subsequent, or preliminary process of bringing awareness to sensations in the body. She outlines what she calls "tracking" as receiving information from the muscles through kinesthetic and proprioceptive sense (166). Tracking is needed when the system is overwhelmed with multiple sensations at one time. Allowing the body and mind to settle can then make space for "being with" to come into play. Awareness is brought first, to the self, to my own sensations, so that I can then release into Eurydice's circumstances and the subsequently evoked sensations, without getting stuck in my own web of selfjudgements.

When I was first tackling "Eurydice's Underworld arrival," my instinct was to play into the emotions of confusion, frustration and general angst, which, as discussed, was a direct product of second guessing myself and getting trapped in my head. This resulted in rushing the discoveries of where she was, why she was there, and trying to figure out what to do about it all. Through "being with," I learned more about my own sensations in the moment of stepping off the elevator platform and into The Underworld. I pinpointed an amalgamation of anticipation and a want to achieve the "correct" way of entering the scene. Placing this pressure on myself was not only the reason behind my muscles tensing, but also led me directly into the trap of playing the emotional quality of the scene. I write in my journal, "the less I thought throughout the scene, the more productive the scene was."

Upon the realization that I was experiencing pressure to perform in a certain way and therefore also experiencing anticipation of doing something "wrong," I knew I had to 
face and bring forward these feelings before I could move beyond them. I was allowing my thoughts to attach themselves to my emotions, therefore prohibiting my emotions from flow and change. Through the practice of "being with" I could actively feel where in the body my breath was getting caught in these moments of self-doubt; it was becoming shallow and limited to the upper chest; therefore, in addition to not supporting my voice properly, it was trapping emotion inside of my body and causing general stress. Through inner physical investigation in concert with, conscious awareness and, the AT term, "inhibition" at the time of mental/physical reaction, I began to understand my habitual patterns of thought, how they render in my body, and how they differ from Eurydice's patterns of thought.

Inhibition, as described by Alexander and restated by Polatin, is “ $[\ldots]$ delaying the instantaneous response to a stimulus; withholding consent to automatic reaction to allow a response that maintains the cohesive action of the whole organism" (10). In application, this process renders as preventing a physical habit from transpiring. By pausing the signal that takes place between the reception of stimulus and the brain allowance for a new choice of action is created. In my experience, inhibition has given way to a chasm of possibilities all of which are free of self-doubt. I realized that selfdoubt is most abundant when my aim is to please others with my performance. The feeling of this doubt also renders a need to comfort myself. This gave way to the realization that many of my physical habits have developed out of a desire to feel more comfortable, which resulted in suppressing action, choices, and general play. However, when self-doubt is inhibited, free expression is then allowed. The body and the mind begin to work together, producing decisions that are based in the authentic desires of the 
character within the moment at hand. When curiosity and a sense of play are alive in the mind and body the individual can embrace the unknown. However, when decisions are based in a comparison of the self to others, or in an attempt to meet a standard, play and discovery disappear and actions become controlled and measured; the body's natural impulses are stifled.

Connection to the body does not require words. In fact, in my experience, words seem to interfere with my ability to freely express my desire, both socially and within performance. I have always felt more comfortable and in control of my immediate space when I am given permission to express myself via the body. However, it is rare that this permission is given, especially within the context of social and professional environments. In these spaces, words are the accepted medium within which personality is expressed and communication is executed. A moment of allowed physical expression within Eurydice was during the choreographed death sequence. Eurydice leaves the Interesting Man's apartment; after stealing the letter from her father out of his pocket, she rushes away. Ruhl's stage directions in this moment say,

She runs, trips and pitches down the stairs, holding her letter.

She follows the letter down, down down [...]. Blackout. A clatter. Strange sounds-xylophones, brass bands, sounds of falling, sounds of vertigo. Sounds of breathing. (25)

In our production, Dr. Calvano brought this moment to life through a slow motion series of tumbles including a "shoulder roll." A shoulder roll is executed from a position of the back making full contact with the floor. The feet rise in the air, reaching back over the head. The toes land on the ground and the feet and the hands assist as the lower part of 
the body flips over the upper part of the body, rolling over the shoulders. Although I was familiar and comfortable with executing a shoulder roll, the process of learning it within the context of the show, and at the slow motion tempo, required that I adjust my habitual execution of it. I began practicing the shoulder roll on the floor, before we had a set constructed. Eventually, when the set was fully realized and we moved into the performance space, there was a ramp that acted as the Interesting Man's steep "staircase" where the roll was to be performed. As the movement became more and more engrained in my body, especially in terms of the slow motion tempo, the more alive I felt within it.

I had been excited about the idea of the slow motion fall since Dr. Calvano shared it with me prior to the start of rehearsals. As I have mentioned, physical storytelling is an area of theatrical development to which I am particularly drawn. I believe that I am connected to body movement as a means of theatrical and personal expression because it is a place where I feel the most capable of "just being." I am able to fully take up space and claim my presence because the pressure of words does not exist. For me, this connects to Eurydice's journey because in The Underworld she is stripped of her words and is forced to reconnect with her body; thus implying that perhaps, she was not fully connected to and/or comfortable in her body when she was in the land of the living.

The thought of Eurydice redeveloping a physical relationship with herself led me to the idea of her sexuality and sexual expression. In The Underworld, the only person she has a relationship with is her father, obviously rendering her sexual life inactive. However, I believe that it is in The Underworld where her desire, and the manner in which it is expressed via physical impulses, is reborn. I drew this conclusion through observation of how she used her body in new ways in order to understand and form 
relationships. For example, when the first letter arrives from Orpheus, she stands on it with her feet (37) - initiating a physical connection in order to find internal clarity. I began to wonder about her life prior to her arrival in The Underworld in regard to her relationship with her physical self and to sex. In her book, The Secret Lives of Girls, Sharon Lamb argues that children, from a very young age, experience sexual feelings. She asserts that through popular narratives, like the Brothers Grimm, girls are taught that sexuality is wrong and that innocence is the only thing that makes them good and desirable.

This pressure of fulfilling certain actions to be sexually desirable overflows into fulfilling certain actions in order to be desirable in any context — to receive approval. This idea of approval is the sensation I reference when I talk about feeling free to own my space versus feeling pressure to live up to a standard or deliver a certain level of skill or product. Wanting to achieve approval in this way, in relation to both my experience and, in my opinion, Eurydice's, especially during the first part of the play, ultimately comes back to the desire to not feel shame, guilt, or the nagging feeling that someone has been let down due to my actions. Lamb takes an in-depth look at feelings of shame and embarrassment in the face of sensations of desire and natural expression. She connects this to physical, sexual desire by making the argument that panic in regard to children's sexuality can be traced back to the Romantic age. She says that, during this period, "children were seen as closer to nature, and in that closeness, girls were seen as quite sexual and in need of education for modesty" (54). This suggests that the "acceptable" actions girls and women are allowed to display in regard to sex are a product of this 
learned "modesty." Again, this modesty seeps into daily actions - limiting full range of expression.

However, when Eurydice arrives in The Underworld and cannot express herself through language and when I rolled down the ramp in slow motion the form of the environment and circumstances is such a specific container that there is no other option but to exist at a fully connected, vulnerable, expanded, and perhaps even messy level. Connection to the body radiates from a deep and intensely personal place all the way through the body and out into the world for everyone to see. However, in Eurydice's case, she does not have the awareness to place self-judgement on top of these moments of primal desire. And for me, even though I could have the awareness to judge, there is no reason to. I am in the middle of a live performance, upside-down in a wedding dress. The people watching me can't do anything about my actions but let them happen and therefore I am free to do the same.

In one of Eurydice's monologues in The Underworld, she is talking about Orpheus and a little bit about their relationship; "show me your body he said. It only means on thing" (51). This line always hit me on stage as Eurydice really hearing the meaning of his words for the first time. Upon reflection, I believe I had this reaction because I think she hears the possibility within it for the first time. The possibility within that line is one of desire expressed only through listening and responding to sensations within bodies and bodies moving in space in reaction to those sensations - the kind of primal physical expression Eurydice begins to find in The Underworld. However, I believe prior to that moment, that she had always been at a loss of how to take in that comment. Perhaps, when Orpheus said it, Eurydice felt, instead of a connection to her 
body and her desire, a pressure to perform in order to please his body and his desire. However, it is in The Underworld where she begins to listen to and trust her own body for the first time and therefore realizes the freedom available there. She also realizes, from my point of view, that a possible reason for her never understanding Orpheus when he said, "show me your body, it only means one thing" was because she never experienced that kind of freedom with him.

This physical awareness and activation in regard to placing trust of actions and expression within the body is further explained and unearthed within many expressionistic endeavors and fields. Tami Spry and Della Pollock, two performance and communication theorists, discuss trust of the body and release from hyper-controlling thought within the notion of, what they call, the Performative-I. In her article, "A 'Performative-I' Copresence: Embodying the Ethnographic Turn in Performance the Performative Turn in Ethnography,” Spry states, “[...] I can [...] use my body as a critical tool of linguistic representation. A performative-I positionality emphasizes this critical potential of interrupting dominant cultural narratives deployed upon bodies by retelling this narrative from the body itself subjected/assigned to those narratives" (344). She is speaking to placing mental and emotional trust in the body. Enacting this trust within the context of writing allowed her to free the mind's hold of the action of the pen, and freed her into a space of untethered thought and thusly manifested writing. Through this mode of impulse driven, guttural expression, she was able to face and make sense of difficult life experiences.

In the article, "The Performative 'I"” by Della Pollock, the idea of trust within physical expression is deepened through a discussion of "what if" (247). Pollock says, 
“"what if" opens a space between what is and what might be [...] This is an ethical space: a space of mobilizing the difference between imagined and entrenched realities [...]" (247). Pollock's theory can be applied to finding a wider range of possibilities of expression within performance, stepping into the unknown space of "what if." She goes on to talk about the results of this manner of expression: "ideally, this self is a mess of errors. She is not so much unruly as superruly, surpassing convention and form on a dare. Errant, playful, and beautiful [...]" (247). In order to become connected the body's "unruly" and unpredictable treasure trove of expressive possibilities risk and bravery must be welcomed.

A particular physical discovery during the rehearsal process allowed me to release fear and step fully into an unlimited amount of "expressive possibilities." Not only was I able to gain a more visceral connection to the external stimuli of the world of the play and the circumstances at hand, but I was able to surpass my emotional reactions and step into those of Eurydice. This discovery was a deep physical connection between my shoulders and my back. I began to think about widening through the shoulder blades and out through the cuffs while exhaling, which produced a significant amount of opening in the shoulder cavity. The top part of the shoulder, the trapezius, relaxed into the neck, promoting lengthening and suspension up the cervical spine and out through the atlas (the tope most vertebra of the spine), while the bottom part of the shoulder draped down around the outer part of the shoulder blade, and under the armpit. The revealed space created a clear channel for emotion to pass out from the chest and the solar plexus smoothly through the intercostal muscles and into and through the shoulders. This physical breakthrough happened one night before entering at the top of the show for the 
first scene with Orpheus. As I was taking in my acting partner and truly listening to him, I started to feel a deep relaxation in the trapezius, which then created a physical opening. The discovered relaxation and muscle release instantly allowed me full emotional investment in the moment and circumstances. Finding this space and access path to emotion allowed me to connect with not just Eurydice's emotional impulses but also to tap into the physical rhythm and energy with which she carries herself.

I have previously discussed how the rhythm of the text gave me some inclination into Eurydice's internal rhythm. However, I have not discussed how Eurydice's internal rhythm dictates actions she makes that are indicated via the text. For example, in the monologue at the beginning of "Eurydice's Underworld arrival," she is trying to understand and piece together the events leading her to this place. There is one part where she attempts to remember her husband's name. She says, "I know his name starts with my mouth in the shape of a ball of twine-Oar-oar. I forget" (28). In this moment, I discovered the action of "to grab"- that she is viscerally attempting to grab the memory from her brain. Professor Rachel Carter, our voice and text coach for the production, also gave me the idea that with these vowels, I could find physical play with the mouth. The action of grabbing, executed through the physicality of my mouth wrapping around the sounds was emotionally fed through the connected stream of energy from my gut out through my shoulders, head and mouth. It felt as though my voice was the carrier of this stream. Finding this energy of connection provided clarity of how to access Eurydice's internal rhythm. The flow and strength of the discovered vocal quality revealed a drive that rendered externally as commitment to her surrounding reality. This is further seen when she refuses to give up hope after several attempts of talking to the audience only to 
discover that she can only produce "[...] a great humming noise" (27). Her efforts even continue after she expresses "[...] a tantrum of despair" (27). She explores the terrain around her with an intention of revealing information. In order to fulfill this goal, she makes immediate decisions that require an immense amount of self-trust and perseverance.

Discovering the personality traits of endurance and persistence, expressed through strong decision making, gave me clear insights into, not only the differences between myself and Eurydice, but also the differences between Orpheus and Eurydice. To further investigate the relationship as well as the disparagement of identity between husband and wife, I decided to research images. At first, I found images that spoke to a certain dynamic of a dominant male and a more submissive female. This was not quite correctEurydice still had agency to make her own decisions within her relationship with Orpheus, like deciding to leave her wedding reception (20). Upon further research and through conversations with our Dramaturg, Janna Segal, I was introduced to the painting, The Lovers, by René Magritte. In this piece, two people are featured, presumably a man and a woman (denoted by the clothes they are wearing), with sheets or some sort of fabric covering their faces. They are wrapped in an embrace, kissing. There is an implied discrepancy between the ways in which they see each other versus the ways they see themselves; their desires, interests, and perspectives on the world do not align. This misalignment transpires in a way that hides them from each other. There still remains an equal love, affection and desire for connection, but their true selves cannot be seen and appreciated. 
In the moment during Eurydice and Orpheus' walk out of The Underworld, she actively makes the choice to go to him and say his name. From the first time she sees him in The Underworld, she is doubtful of his identity. She says, "That's

Orpheus?[...]Where's his music?" (60). When they are exiting and she speaks his name he turns around and says,

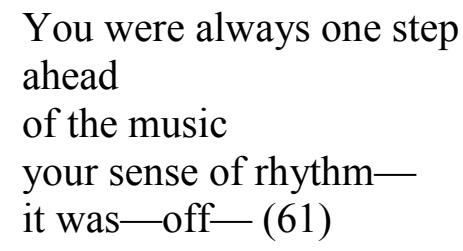

He implies an energy, a drive in Eurydice. Right from the beginning of the play, it is obvious that the internal rhythms of these two characters is incongruent. In the first scene there are many moments when Eurydice attempts to get Orpheus' attention but he doesn't see, recognize or consider her with the same care and attentiveness that he gives to his music. For example:

EURYDICE. What are you thinking about?

ORPHEUS: Music.

EURYDICE: How can you think about music? You either hear it or you don't.

ORPHEUS: I'm hearing it then.

EURYDICE: Oh.

(Pause)

I read a book today. (10)

The pause indicates a searching action from Eurydice. She is looking for engagement with Orpheus, but all he can hear is music. Because of that, her acceptance of and trust in herself do not fully realize until she reconnects with her father in The Underworld. This again points to a disconnection she felt in the world of the living surrounded by social pressures to perform desire a certain way. From my perspective, there was, inside of her, 
a lack of understanding of how showing her body can "only mean one thing" (51). Her energetic rhythm is always there but without the connection to her body at the start of the play it is not accompanied with the same amount of confidence as at the end when her desire free-flows through her physical choices. Neither Orpheus, nor Eurydice, were ever able to express their true selves with the other because they were looking for something that was not there. Magritte's painting is a wonderful visual example of this blindness.

In my opinion, the personality traits that most separate Eurydice from Orpheus are her open reception to whatever her current environment or situation may be and her persistent curiosity and desire to gather information, just for the sake of knowledge. Stepping into seeing the world in this manner-in a way that attached very little, if any, judgement to the elements of the surrounding world or to self-executed actions-required a level of relaxed investigation that was new for me. Accessing this peaceful sense of discovery was possible through the process of "just-being" and coming into my own sensations, facing them, moving through them, and maintaining a connection to all external stimuli. Beginning from this open and connected place of listening and responding provided me with a passage into crafting more specific and nuanced character choices. 


\section{CHAPTER FOUR: THE PYRAMID}

When crafting the character of Eurydice, there were many layers of trial and error leading to the eventually drawn conclusions about choice of portrayal. In his article, "The Physical Genius," Malcolm Gladwell says, "[...] practice changes the way a task is perceived." This applies to character creation because the deeper one goes into getting to know and understand a given character, the more the layers of that character are developed. Gladwell uses the image of a pyramid to demonstrate how layering is a crucial step to becoming a "physical genius"- an umbrella term under which actors and performers fit. The idea of the pyramid can be applied to the layers of an actor's character development process - the wide foundation functions as the actor's first impressions of the character and the narrow and focused jumping off point as the actor's full embodiment of the character.

In his piece, Gladwell begins by walking the reader through a surgical procedure as executed by the famous and virtuosic neurosurgeon, Charlie Wilson. He then introduces the two other subjects who will aid in the demonstration of his argument: Wayne Gretzky and Yo-Yo Ma. Gladwell says, that "the temptation is to treat physical genius in the same way that we treat intellectual genius $[\ldots]$ a physical version of I.Q.," but the truth is, physical genius is made up of multiple layers that are hard to parse out 
and label. He goes on to explain that physical geniuses have a keen ability to visualize all the options possible and then choose the best one for the given situation. However, the trick comes in the choosing. Gladwell says, it is an exercise "in a certain kind of exhaustive and meticulous preparation." This produces a steadfast work-ethic and discipline within practice habits leading up to the moment of performance. This philosophy demands having a personal preparation process, within the context of stage work in general, but especially within character development. When all the layers of character work have been explored, embodied, tweaked, changed, re-assessed and reembodied, the actor can then allow these practice methods to go away and trust that the character lives inside of them. The mind and body are then free to produce an immediate and subconscious, character accurate, reaction in any given moment.

To begin the process of creating a relationship with Eurydice, I read the play multiple times, working on line memorization and collecting first impressions of her. I created a Pinterest board of images that were inspirational in terms of how they evoked or reminded me of Eurydice's essence or qualities or traits. Gladwell talks about the design of the physical genius process. He says, "if you think of physical genius as a pyramid, with, at the bottom, the raw components of coordination, and, above that, the practice that perfects those particular movements, then [the] faculty of imagination is the top layer." When transposing this model to one that applies to the creative process of the actor, the bottom layer consists of the technical components, such as memorization, honing and refining instincts and observations about the character, channeling those instincts into physical and vocal choices, and exploring the differences between the character and the self. There is a discipline involved within this bottom layer that is crucial to the 
successful development of the subsequent parts of the pyramid. In her book, The Creative Habit, Modern Dance Choreographer, Twyla Tharp speaks about how the development of creative material relies on habitual discipline. She talks about her morning routine of going to the gym and how she has endowed it with a ritualistic quality. She says, "the moment I tell the driver where to go I have completed the ritual. It's a simple act, but doing it the same way each morning habitualizes it — makes it repeatable, easy to do...the quasi-religious power I attach to this ritual keeps me from rolling over and going back to sleep" (15). She goes on to discuss how creating ritual is a crucial step to any artistic process.

I had a few different rituals over the course of bringing Eurydice to life. In the beginning, my ritual was becoming intimately familiar with the text. To accomplish this, I read the text many times; and I wrote all of my lines and cue lines out on flash cards. I would begin each morning with a review of these cards, making notes about my initial impressions of Eurydice. My first observations consisted of her likes and dislikes, where she seemed to excel in life, and where she seemed to struggle. At first these findings were somewhat superficial. However, they were the seeds that allowed the more complex layers of Eurydice to grow and flourish. One of her interests that popped out immediately was her love of books and reading. In the first scene of the play, she says to Orpheus, "I read a book today [...] Don't you want to know what it was about?" (10). I noticed a desire to share what she had read; her enthusiasm spoke to a fire inside of her that was stoked through reading and becoming "a larger part of the human community" (10). This started to suggest that she was a thinking person-someone who loves to learn about many ideas and come up with her own. This is also confirmed and deepened on page 41 
when she is in The Underworld and her father is helping her to re-learn her vocabulary. She passionately moves from one word to the next with the phrase, "teach me another" (41), and interprets the words through transforming their definitions into poetic paintings: "peripatetic: a learned fruit, wandering through the snow" (41).

As these discoveries were made, I began to draw inferences through subsequent research, such as image finding and beginning play with physical choices. I started to experiment with where in the body Eurydice leads from and where she might hold tension or physically react when emotionally prompted. The one physical habit of hers indicated in the text occurs when the Interesting Man says, "I'll bet you had an interesting thought today for instance. I bet you're always having them, the way you tilt your head to the side and stare $[\ldots]$ " (24). This textual evidence in combination with my deduction about her being a thinking person led me to experiment with the idea of her leading with her head. I started to play with physically answering the question, what if every idea she has, every action she makes, begins with a spark releasing from the head? This experimentation opened a door into further connection with Eurydice. I began to channel all of the impulses I felt into the head which meshed in an inspiring way with the openness in and connection to the shoulders, as previously discussed.

I then began to have many discussions with the actor who played Her Father, about the overlapping personality traits between these two characters. Together we talked about the prominent analytical abilities that they shared and he expressed how he believed that Eurydice was the one, out of all of his children, who was the most like him. I agreed with this inference because, when Eurydice reconnects with Her Father, he helps her gain her memory, but she also ends up gaining information, about the world and 
herself, that surpasses what she knew before. The rediscovery of her love for words and language as demonstrated on page 41 , as well as her desire to know countless stories about her father and her family $(40,41,42,46)$, pointed in the direction of him being able to provide insight into her identity. The connection between the two of them is further exemplified when Her Father is teaching her a song from his childhood, I Got Rhythm, and they both start to sing it. They are interrupted by The Stones and Eurydice says, "I'm not a very good singer" to which Her Father responds, "Neither am I" (47). Her Father is able to fill a hole that had formed in her when he died. In turn she connects with herself in a way that allows her to face certain things in her life, like her relationship with Orpheus, see them for what they really are, and deal with the consequences of those realities.

Understanding that Eurydice's gained knowledge of herself and sense of self in regard to the formation of her future, stemmed from reconnecting with her father, enabled me to see the nature of her character arch and to appreciate that it was different from that of other character arcs with which I have experimented. Characters I have built in the past require a recognition of where the character begins and where the character ends upmost of the time there is a very clear change that happens. In Eurydice's case, the change is more nuanced and is mainly in regard to self-awareness and engagement with her authentic desires. For example, when Eurydice chooses to return to The Underworld after she catches up to Orpheus on their procession out, she says,

Everything is so greyit looks familiar-

like homeour house wasgrey - with a red door- 
we had two cats

and two dogs

and two fish

that died- $-(62)$

This is the first time that she produces her own knowledge about her home and her childhood. These realizations possess at least enough emotional potency to motivate her final decision to leave Orpheus behind and return to The Underworld, to Her Father. For me, there was so much identity wrapped within these nostalgic lines. Remembering the details of where she grew up, the environment and the connections, held an immense amount of self-recognition and understanding. In order to grasp this more fully, I had to flush out her progression and uncover deeper layers of her personality. I started to really pull apart how she ticks. Eurydice's connection to her mind and to the world via thoughts and ideas was the starting point for revealing the core of her personality.

Other initial observations I made that helped feed certain conclusions about the underlying motivations behind her actions, included her hatred of parties (17), her repeated statements of desiring a bath upon her arrival to The Underworld: "I would really love a bath" (30); "I want a bath" (32); "would you run a bath for me" (35), and her love of reading and discovering ideas (10). While these acts of solitude can serve many different kinds of people, they are nevertheless, acts of solitude and give confirmation that she at least enjoys, if not needs, this time alone. In other words, from these acts, like reading and taking baths, I deduced that she is someone who can recognize the difference between being alone and being lonely. This inferred desire for solitude in combination with the way in which she relies on herself to make decisions and solve problems, such as when she tells The Interesting Man to close his eyes, making him believe she will kiss 
him, but then taking the letter from his pocket instead (25), led me to the choice of making Eurydice an introvert. That is to say, I decided that she reaps the most energy from life when she dedicates time to re-connect with herself. As mentioned, part of flushing out the bottom part of Gladwell's pyramid, as applied to character development and the artistic process at large, is separating out the differences between the actor and the character. As I am a person who receives energy and motivation from others, a.k.a, an extrovert, this realization was a wonderful step into understanding how to approach organizing my own traits within those of the character. What then started to come to light was how Eurydice relies on herself for validation and approval before making decisions, whereas I frequently rely on validation and approval from others in order to make decisions.

This major conclusion pinpointed the psychological difference between myself and Eurydice. The next question I had was, how did this psychological difference impact physicality? Up to this point, the main physical choice with which I had been playing was leading from the head. This led to a couple of other small physical discoveries, such as a narrow stance (sometimes the feet were touching each other) and an occasional gesture of the palm, fingers flattening, and the whole hand being used to express, but the arms remaining low with very little bending of the elbow. I was able to assert that the accruing gestures and mannerisms stemmed directly from the choice of the head leading her locomotion because of the spine's orientation. Because Eurydice's physical identity, the manner in which she carries herself, includes a relatively free neck and head, the spine then drapes down her back, giving into the oppositional pull from the tail bone. This means that her torso is very well supported and she has full access to her breath; her 
impulses for communication then are going to be largely felt through the chest, the solar plexus, the head, perhaps the pelvis, but not as much within the extremities. When the torso has a wide range of expression via full use of the breath, it is less likely that superfluous gestures will be used.

Betsy Polatin talks about breath in the body and how to allow for, what she calls, "Optimal Breath" (62). She describes an optimal breath as including "movement of the whole torso $[\ldots]$ especially engaging the ribs $[\ldots]$ " (62). She describes how optimal breathing is accomplished when the torso is operating in a three-dimensional manner. She says, "three-dimensional breath has a side-to-side quality to it... an up and down quality to it $[\ldots]$ [and] a front-to-back quality to it $[\ldots]$ " $(60)$. She goes on to talk about the back's importance to this process: "because the bulk of the tissue of your lungs is in back, you want to make sure you feel your back moving" (60). I discovered that Eurydice is a person who has been able to maintain this natural connection to the back and to threedimensional breath. Her "[...] breath responds to what is going on in [her] system", (71). When confronting and interacting with external stimuli, it is the best case scenario " $[\ldots]$ to be able to move, to be active, and to be with other people and still breathe fully" (71). Eurydice has this full capability.

Herein lies the physical difference between myself and this character. I am a person who sometimes solely relies on my extremities for communication and struggles with connecting to my back - therefore failing to allow my breath into my back ribsespecially when facing external stimuli. There is a sensation of needing to bring myself to those around me, of needing to assess what they react positively to, and then attempting to produce whatever that might be. Eurydice, however, does not do this. She is able to 
stay with herself, and therefore draws people to her rather than pushing herself onto others. Unveiling this insight into Eurydice's physical life made me have deeper realizations about moments in the text in regard to her actions and choices. For example, early in the play, when she hears from the Interesting Man that he has a letter from her father, she, almost immediately, jumps at this opportunity and follows him to his apartment. With awareness of the ease of breath in her body and her connection to her back, I then recognized this action as a sign of innate bravery and impulsivity. This then brought me a step closer to fully unpacking her journey within the story. It is not that she gains agency necessarily, she has quite a bit of self-empowerment from the very beginning. I started to infer that it was more a question of how she owned this power; how she publicly claimed her agency. Following this inclination meant that I first had to take on the challenge of feeling her power in my own body and being able to act on it.

In order to channel Eurydice's energy, it was necessary for me to find a more stable and complete connection to my back. This required me to understand and connect to a fuller exhale and a deeper freedom of the breath. Accomplishing this meant inhibiting and redirecting many innate, sensational impulses. Polatin breaks down the process of tapping into the optimal breath. She says, "when you exhale properly, all of your ribs spring back open to inhale, making space for a new breath $[\ldots]$ To foster this springlike quality, allow your spine to lengthen upward, while your ribs drape downward as you are letting the air out" (62). Practicing and eventually incorporating this energy of thought into my awareness of my breath mandated that I let go of the feelings of anxiety, particularly in relation to a want to perform, both on stage and socially in life, to a standard. It also made me slow down my overall physical and mental tempo. Releasing 
the muscles in my "ribs and belly that interfere with [...] breathing mechanisms" gave way to a "[...] greater airflow and larger vital lung capacity" (67), that gave me opendoor-access to my emotions and also made me feel like I was capable of anything. From here, I could then more accurately and fully represent Eurydice's independence and curiosity. She is crafty and trusts herself to handle any situation she lands in, for example, when she is attempting to get leave the Interesting Man's apartment but does not want to go without the letter he promised. When he says, "my lips were meant to kiss your eyelids, that's obvious," she tricks him and responds with, “close your eyes then!” (Ruhl, 25). She jumps from one tactic to the next in her fight to get back to her husband but also to get what she came for- the letter. She is a fighter and she does not like to give up.

Becoming familiar with how to connect to my back and thereby diving fearlessly into a kind of breath that "[...] radiates out to the arms, legs, and head" (Polatin, 59) was the main technical piece that I needed to master in order to step into Eurydice's ferocity and dedication. Eventually, this physical connection became so recognizable to my body and mind that I could find it, find her, without thinking about it. Gladwell refers to this process as "chunking." This is the second layer of his pyramid. He says:

A chess master, for example, can look at a game in progress for a few seconds and then perfectly reconstruct that same position on a blank chessboard...because hours and hours of chess playing have enabled them to do what psychologists call "chunking." Chunking is based on the fact that we store familiar sequences... in long-term memory as a single unit, or chunk...when the chess masters see the board from a real game, they are able to break the board down into a handful of chunks - two or three clusters of pieces in positions that they have encountered before.

Chunking actually relates to many components of stage performance including, cue and line memorization, blocking, physical movement, and (the one being examined here) 
character embodiment. As Gladwell describes, once the chunking process has transpired, the images and corresponding feelings are stored in the body. The object then becomes to connect with and put full trust into what the body knows. This leads the performer into the last, top-most section of Gladwell's pyramid, imagination.

Once the information has been chunked, the mind can allow the body to be in full control. In fact it is most useful for the mind to hand over the steering wheel in this manner. If the mind does not fully relinquish, it can interfere with the body's capability of enacting and committing to the chunked game plan. Gladwell speaks to this when he writes, "Yo-Yo Ma says that only once, early in his career, did he try for a technically perfect performance." The act of expression cannot be fully planned or sought by the brain to be "perfectly executed." It can be prepared for, thus the act of chunking, but not dictated. Yo-Yo Ma confirms this theory as he goes on to discuss his experience of his attempted perfection: “"I was playing a Brahms sonata at the 92nd Street Y. I remember working really hard at it, and in the middle of the performance I thought, I'm bored. It would have been nothing for me to get up from the stage and walk away. That's when I decided I would always opt for expression over perfection"” (qtd. in Gladwell). Performing a piece of music or creating art of any kind is an expressive act and can be equated to any other expressive act like communication, sex, giving a presentation, public speaking, posing for a picture, posting on social media, dancing, laughing, giving someone a hug, etc. The imaginative expression of desire requires trust of the connection between mind and body, and requires the mind to get out the way. This is the step that requires diligence - it is easy for the mind to panic and demand to take back the reigns. Following the brain's impulse in this moment can lead to getting trapped in one's head. 
Therefore, it is necessary for the body to inhibit this take over. This leads the performer into a version of willpower. 


\section{CHAPTER FIVE: POWER OF WILL/STRENGTH OF HEART}

The structure of the Gladwell pyramid has proven a wonderful guide within the creation process, especially when it comes to the idea of willpower. For the majority of my life, essentially up to the Eurydice rehearsal process, I had viewed willpower as suppressing emotions in the body that seemed to interfere with the situation at hand. My perception of enacting will was to hide away real opinions and thoughts when they might be controversial and to just power through within the given structure and/or limitations. Generally, when asked, I would have defined willpower as mental dictation over my actions. However, what I learned through the development of this show was that dominance from the brain is actually the antithesis of willpower. For me, willpower now lies within activation of and connection to the body, in balance with reception of the immediate space, environment, and all external stimuli. Willpower comes in when the layers have been crafted; when the pyramid is fully in place. The idea of control has morphed for me into discipline and routine, as Gladwell discusses. It has morphed into the ability to spend an extended amount of time allowing information and action to seep all the way into and through the body, so that when the moment of performance comes, not only does the brain have full reliance on the body's ability to produce, but when 
something goes wrong, the body and mind are able to work together to recover, to let go of the "mistake" and to move on - all within a matter of seconds.

Once we moved into the final stages of technical rehearsals and eventually into performances, bringing the body back to a place of connection when mental or physical habits came into play was the element that ultimately allowed me access to Eurydice's drive and quick decision making. Returning to connection also kept me focused, engaged, listening, and unafraid while moving through each moment. Developing awareness of specific external stimuli that trigger disconnection relates to Polatin's sentiment that "the first step in your process of discovery of an expanded self is to begin to become aware of, and learn to recognize, your own patterns of use and misuse" (17). The idea of habits and my personal experience with them came into play in the middle of the play, when Her Father is teaching Eurydice words. During rehearsals I would notice personal habits creep in when working with intentions, such as 'to curiously wonder', 'to investigate', and 'to think.' For example, there was quite a bit of brow furrowing and habitual laughter that strained my vocal folds. There was also a prominent sinking into my hips that made me lose connection to my lower body. As soon as I became aware of these physical misuses, I could assess them objectively. I could ask myself, are they correct for the character? If they were, I could consciously make the same physical choice but with use of my whole, connected body, rather than having physical choice come from a place of disconnected, subconscious habit.

Bringing awareness to my thoughts and subsequent actions, inhibiting the habitual, and opening my body to an integrated form of use, allowed me much more access to Eurydice's thought patterns and produced physical actions. In rehearsal, when I 
used inhibition, Eurydice's impulses were more readily available. I then found a whole new spectrum of physical expression: openness and release through the eyes, fingers resting against the lips, knees bent, and feet close together. I also started to tap into the character's mentality - visualizing the images described by Her Father as he defined the words. It was through connection, inhibition, and imagination that I was able to place trust into my physical body to create something new and different from myself. Willpower then comes into place within the act of "maintaining" inhibition and connection. I put maintaining in quotes because, in the context of the Alexander Technique, attempting maintenance of physical and mental connection, results in tension and physical holding. The objective becomes, filling the discovered physicality and mentality with breath, life, and fluidity; allowing the body to change as new stimuli is received. Professor Carter frequently says, "you feel as though the body is in constant motion." This sense of constant flow does raise the risk of slipping back into the habitual body and mind and loosing connection to the character. However, this is where I have redefined willpower for myself. It has been my habit, whenever I feel I have tapped into the character in a strong and integrated manner, to do everything I can to hold onto it and if it moves away from me or I do something that feels untrue to the character; the result is frustration and disappointment and subsequent mental attachment to these emotions. Willpower is the ability to risk falling into an action, impulse, or line delivery that is untrue to the character and then be able to immediately re-connect and return to a place of inhibition, physical connection, and investment in the imaginary details of the world and circumstances of the play. 
This process of re-connection then begs the question, how does that happen? Is it not control and effort that enables return to an inhibited place of accessibility? In an interview about connection with AT professor, Rachel Carter, she made the statement that, "connection is meeting yourself where you are." Therefore, within the process of reestablishing a connected, open and inhibited body, it is necessary for the first step to involve immediate recognition and acceptance of wherever the mind/body went when disconnection happened. For example, as I said, my habit had been to land in selfdisappointment and even ridicule and to get trapped there. I have come to realize that becoming stuck in emotion in this way is a sign of panic and an attempt to rid the mind and body of emotion. Pushing away whatever emotion comes up has proven the number one way to sink deeper into that emotion, as opposed to allowing it to flow through and move on. However, if, for example, a choice is made on stage (this also applies to life but I am contextualizing it within performance) that feels disconnected from the character, it is crucial for the actor to bring themselves to these emotions, to accept the doubt or frustration or anger. Once the emotions have been addressed and embraced, the system is then able to tap into and place trust in the "[...] tools in which to recover and undo" (Professor Carter). These tools are the elements that have been discussed, such as physical awareness, inhibition, and commitment to the moment at hand.

The place where I typically get caught the most is in released discomfort from slipping into habitual disconnection, which I have connotatively endowed with the feeling of failure. Resting in a place of failure, looking failure head on and accepting its presence, is a very large feat for me. When I feel as though I have failed, it is easy for me to then feel as though I am wrong - that everything I have done is wrong. What I have 
learned, however, is that disconnection typically comes from following an impulse. It comes from living freely within my sense of connection to the character, taking the liberty to play and then going a bit too far and landing within a pool of my own habitual forms of expression. I have followed my own desires and strayed from those of the character. There is an immediate sense of dread that accompanies this trajectory.

In order to assess the reasons behind this cause and effect, I return for a moment to the previously discussed Brothers Grimm story, Our Lady's Child. The protagonist followed her desires and was punished. She allowed her natural expression to shine through when she made the choice to disobey Mother Mary. This decision resulted in her voice, a necessary tool in the process of expressing one's desires, being removed, thereby sending the message that girls who follow their desire are "bad girls" and do not deserve the ability to express themselves. Girls are shamed and punished for the expression and exploration of their curiosity and naturally felt desires, thus making it difficult for them to place trust in themselves.

A personal example of the shame that can come from authentic expression of desire happened this past summer in the context of performance training. I was watching a scene that my peers were doing and I laughed. My laugh is an expressive laugh and I have had a turbulent relationship with it. However, at that time, I was consciously making the choice to allow it to be free and come out in whatever way it pleased. A few moments later when the instructor was giving feedback to the scene, he said, "well you might not have been thrown off in that moment if this one hadn't let a whole horse come out of her mouth." No one laughed, because his intention had not been to make a joke. Feeling like I had failed and done something "wrong" existed, and, at times, still exists in my body 
with intense potency and power. However, the realization that has finally allowed for some release of this shame was that the only way to learn more about myself and, in the context of performing, the character or the objective at hand, is to cross the line and become disconnected sometimes. It is necessary to follow one's own impulses and desires and end up way off course in order to discover the direction of the path and ultimately to use those same impulses and desires in order to re-channel them into connection and inhibition.

Over the course of the Eurydice rehearsal and performance process, I am not sure that I was able to fully step into this idea of facing the feeling of being wrong, embracing my self-perceived failures and re-directing my energy into a more productive use of myself. There were moments where this process flowed easily and smoothly out of me, to a degree where it took me by complete surprise. However, the journey of getting to know and bringing Eurydice to life in my own body has revealed a lesson of agency that I had not yet learned. Over the course of the play, Eurydice makes many "mistakes." One of which, ends up being the reason she dies and goes to The Underworld. However, her ability for committed action and progression no matter where life brought her, showed a sense of power. Connecting to this power meant that I had to wake up a part of myself that had been dormant for some time now. I have talked about how, when Eurydice and Her Father are re-united, Eurydice is able to claim her power openly and unabashedly. She reaps from Her Father a certain amount of validation that she had not known she was missing. Her power remained when Her Father died, however, because she did not have him anymore, there was no one besides herself who continued to stoke that fire. So while it did not lessen, it also did not grow. Through relationship development with the actor 
who played Orpheus, we discussed how both of these characters depend on each other in a way that allows them comfort and safety. They do not necessarily lift each other to new heights, they simple create mutual stability and stasis. When Eurydice finds Her Father again, she remembers what it is like to have someone challenge her in an exciting and empowering way; encouraging and prompting transcendence of mind, body and spirit.

Reconnecting with Her Father gives way to her reconnection with words and thoughts and ideas. She says:

Orpheus never liked words. He had his music. He would get a funny look on his face and I would say what are you thinking about and he would always be thinking about music. If we were in a restaurant sometimes Orpheus would look sullen and wouldn't talk to me and I thought people felt sorry for me... But I wanted to talk to him about my notions. (51)

With Her Father, her notions are given the space and the enthusiasm to come alive. It was at this point in Eurydice's journey with her sense of power and agency that I repeatedly got stuck. I found the evoked emotions when interacting with Her Father included prosperity and motivation for life and creation. There was a spark ignited that captivated and stirred Eurydice's, and subsequently my, inner life. I started to realize how this spark, once lit, continued to grow and evolve through the rest of the play. Therefore, there was a palpable build within the story, leading up to the moment Orpheus arrives in an attempt to retrieve his wife and bring her back to his world. It was necessary to confront these feelings and become fully immersed in them in order to crack them wide open and follow them through the point of realization, which is when Eurydice makes the choice to catch up to Orpheus as she follows him out of The Underworld. She gets right behind him and says his name, startling him and results in his turning around, which causes the world to fall apart (Ruhl, 60). From the moment the spark is lit all the way through to this moment 
of the exiting journey, discomfort crept in and interfered with me following and chasing the spark.

The origin of my discomfort came within the process of internal physical connection balanced with commitment to the external imaginary circumstances. I would be fully connected to the events and then suddenly hit a block and find myself slipping back into habitual mannerisms and getting caught up in false actions and reactions. I think the reason for this occurrence was two-fold. In one regard, it was extremely vulnerable to allow myself to approach the ownership of agency with assertive boldness. But also, connecting with Her Father in a way that filled Eurydice with a new sense of purpose and strength elicited strong pangs of raw emotion. In my personal life, I am experiencing a form of losing my own father. Through connection with the circumstances of what Eurydice was experiencing, there was no way to avoid scraping up against my own emotional baggage. It then became necessary for me to increase the volume of ownership with which I approached the emerging sensations. The process of investigating how to find acceptance of, what felt like at times, a reservoir of very personal pain in order to then allow it to flow out of me and be channeled into Eurydice's expressions and reactions in a healthy way mandated that I address my internal state. This investigation led me once again to the connection of my shoulders to my back. I have previously discussed how tapping into this connection, brought me closer to Eurydice, emotionally and physically. When I experienced this block of accessibility due to a resistance to explore something that felt a little too painful to use on stage, I realized that my shoulders had become disconnected from the rest of my body. 
In one of my AT lessons, Professor Carter worked with me from a position of lying down on a table. We began to focus on emotion in the body, zooming in on the ways in which I was physically cutting off emotion within my body, specifically, the problematic shoulder area. While we were physically exploring, Professor Carter asked me to identify a moment in the play where I feel the most blocked. I told her it began when I first begin to really go back into her relationship with Her Father, towards the middle of the play, and builds all the way through to the end, when she comes back to The Underworld and discover that he has dipped himself in the river. I commented that the sensation of being blocked was probably the strongest during the last scene when I wrestle with the reality of him being gone forever again. It is especially hard to connect in this moment because when I tap into vividly conjuring images, I find I watch my own father drift away from me, which immediately makes me physically brace against the released emotion. While we were working, I made the observation that I could feel the emotion flowing freely up to my collar bones and then getting stuck. In this moment, I stumbled across a sensation that has been present in me for quite some time now, but that has always made me uncomfortable and therefore led to avoidance. I decided to inhibit avoidance, dive in, and investigate. Through the process of facing this sensation, I discovered that it could be appropriately identified as apathy. Upon labeling this feeling, I immediately felt a rush of relief and a whole chasm of space open up between my upper ribs and armpit, connecting my shoulder into my back, and releasing the tension in my collar bone.

I understand that the word and concept of apathy, can be negative. Therefore, this realization took me on a linguistic journey. One of the synonyms I found for apathy is, 
"indifference." Indifference is defined as a "lack of concern." The word concern peaked my interest. In my mind, I associate concern with worry or anxiety and define it as feeling upset and therefore had the reaction of: "ah-ha!" of course I was relieved to shed the constant concern that seems to fill my body. However, when I looked up the definition of "concern" in Webster's New World Dictionary, I was surprised by what I found. The first couple of descriptions included, "to relate to; to be connected with; to interest or be involved in." It was only the very last definition that described it as, "to worry, or cause anxiety." I then realized what I had unearthed: through acceptance of apathy's presence in my body, and by digging out what it was specifically about apathy that made me want to accept it, I was able to release feeling troubled, worried, and/or disrupted by any one event. I could now find a place in between pushing with unnecessary effort in order to move past a sensation so I could execute an action and sinking back into defeat, thus resulting in habitual actions.

Tapping into a lack of worry, a loss of feeling disquieted, gave me the perspective needed to enjoy the process. Ultimately, I think the more accurate word for this discovery is objectivity. In the interview with Professor Carter she said, "[...] inhibiting one's initial reaction to something, allows for a new response, allows for a sense of empathy for the situation at large, thus giving way to a larger, more objective, perspective." For me, this idea of apathy, of a lack of concern, of objectivity, allows there to be less weight on events. It allows unaffected, pure, re-connection to the surrounding environment and the imaginary circumstances to happen more easily because the natural order of things is understood in a more visceral way - there is a primal energy within apathy. It is at least 
one possible entryway into protecting oneself when vulnerability from personal connection to the events is in play. 


\section{CONCLUSION}

Accessing and revealing authentic desire in the body is a terrifyingly vulnerable venture, especially within a socio-cultural atmosphere of specified standards of conduct within human interactions. Efforts to preserve social smoothness can lead to desire-based impulses becoming locked inside the body_-shrinking into stiff, hidden secrets. In my experience, and based on the elements discussed in this document, the process of denying true expression and holding physical tension stems from mental recognition of social rejection or judgement. The body cannot find ease within action and reaction unless a freedom to launch into an unplanned response is allowed. The trick comes in the aftermath, the ability to own whatever response is evoked. This ownership requires selfawareness, knowledge, and acceptance.

For myself, I have discovered that acceptance is only possible through meeting the self where it is in time and space. Rather than fight the mind and body, attempting to rid it of whatever state it might find itself in, courage is needed to trust all internal sensations that arrive and allow them to morph into actions. As Stephen Wangh talks about, as long as awareness is maintained, full and complete trust can be placed into the body's impulses. This is not something that can be held onto-impulses arise based on emotions and sensations that are constantly flowing and changing within and throughout 
the body. In order to connect to these impulses and join them on their ride, it is necessary, for me, to take comfort in the fact that thoughts and emotions are separate entities. As emotion flows, like Betsy Polatin discusses, there is no need for thoughts to cling to them — they can move right through. This is not necessarily a reliable process. Internal, physical connection will not always result in freedom of expression and strength of presence. There will of course be moments when the brain wraps itself around an emotional sensation and refuses to let go.

It is in the moments of discouragement, self-doubt, and second-guessing oneself, that connection allows determination to keep willpower alive in the body. It is necessary to find the motivation to return to an internally connected body and mind, so that the self is able to re-connect to the external world, re-connect rather than hide, run away or give up. As discussed, this document aims to be a reflection of, and momentum towards, building my own definition of willpower and contextualizing it within girlhood and specifically within the transition from girlhood to womanhood. However, the process has resulted in a discovered system, or method, for a fluid allowance of willpower into the body rather than a stagnant definition. For me, the act of will has become just that, an action, a verb, much more than a noun. Finding the will to not just acquire a basic understanding of a new skill or activity, but rather, to dive into that skill; allowing myself judgement free time to travel through the layers involved in the action, is, I have come to find out, a circular process. This is where my continued growth and exploration will be directed - in the practice of approaching all stimuli through the act of the following description of willpower. 
Please note, as I break this process down, for the purposes of clarity and efficiency, I will use the word "step." However, each step is closely intertwined with the others and, once embodied and practiced, the parts, or steps, become byproducts of each other. Thus, the system becomes more of a flow, or a wave, than a step-by-step process. That being said, the first step to allowing willpower into the body, is relaxation-I might note that when first embarking on this journey, this sentiment would have seemed ridiculous. It would have seemed counter-intuitive that relaxation could be related to enacting power of will. When emotion arrives in the body, it is possible and I would argue necessary, to respond by sinking in. That is to say, there is acceptance within the action of relaxation. The next step is objectivity, and/or discovery. The circumstances are observed and taken in with a sense of ease. There is distance between personal feelings and the reality of the situation. This impartiality then allows for a readjustment of tactics and the next step, initiating action, such as communicating with and responding to external stimuli, can be entered into. Because objectivity has been found prior to response, there is a sliding motion in the manifested communication; a smoothness that, had relaxation and objectivity not preceded, might have come out as over-indulgent emotionality or with a jolting energy.

The effect of moving through the process of enacted willpower in this broken down manner is a constant recalibration of energy in order to find balance between emotional drive and commitment to staying in and working through the given moment. Once the step of action has been made, there is a need for ownership. Trust exists within this step. All efforts have been made to relax, see the world through an objective lens, and respond with a perfectly proportioned cocktail of care and authenticity. This leads 
right into the step of alertness: staying committed to the environment, working through the energy in the space and taking responsibility for one's presence within the space. The next step is determination. Again, prior to this exploration and development, I might have said that determination is the first step to willpower. However, now, I realize that determination is only possible once relaxation, objectivity, initiated action, ownership and alertness have been found. It is then necessary to return to a place of allowing each of these in, of consciously asking them to be present and to flow through the body and mind in an easy, repeated, rhythmic manner. This is the point where it is very easy to get frustrated, discouraged, and overly invested in the circumstances, becoming disconnected from the self and subsequently disconnected from willpower.

Therefore, determination does not mean powering blindly through the reality of a situation, whether on stage or in life, it means, returning to asking the self, can I relax? Can I see these events objectively? Can I initiate action? Can I own my responses? Can I be alert and present in the space? Eventually, the answers become yes every time and the space between the steps or questions, gets smaller and smaller until they are all blended together and happening more or less automatically. Although, energy of thought always remains present. Once this flow has been established, the next step is being honest with oneself. Again this is very tied to determination. Essentially, self-honesty is the ability to genuinely answer the above questions. And, if one of the answers is no, it is then necessary to relax into that fact, accept it, see it objectively, initiate a response to this "no," own whatever happens, remain alert and open to the heart's truth (stay with the sensation of "no"), and find determination to remain in this cycle until the heart shifts and the "no" melts away. 
The last two pieces of my willpower flow chart are freeing thoughts from emotions and embracing whatever energy is released from the body over the course of the willpower process. Staying committed to the cycle means bravely facing everything that comes up within the self. Determination to move back through the steps means redirecting any and all sensations that arise that could lead to giving up and/or trying to retreat. These sensations include, but are not limited to, fear, reluctance, avoidance, anxiety, and planning/control — they are not a part of the willpower equation. In order to make progress and move forward, all one can do is embrace the moment and embrace the consistent internal change that comes from forward momentum and constant connection to the willpower cycle. It was through the act of stepping into the character Eurydice, that I was able to experience this kind of constant motion. Motion that is not frenetic or hyper, but simply engaged and connected. When thoughts of judgement arise, like doubt or selfridicule for getting frustrated along the path, it is important to remember that thoughts are not intrinsically tied to emotion. It is possible and healthy to fully feel whatever emotion is evoked within each step of finding willpower, but thoughts do not have to dwell on the feelings that arise. Whatever energy of emotion is unleashed is embraced and relaxation, the first step, is found again. Embracing emotion leads to relaxing into its presence, accepting it and then understanding it objectively and moving through the steps of the willpower flow.

In her final monologue, Eurydice travels through each of these phases of my willpower cycle. At this point in the play, Eurydice has just made the choice to leave Orpheus and return to her father and The Underworld. However, once she is back, she sees that her string room has been dismantled and her father is seemingly asleep. She is 
then informed by The Stones that he has actually dipped himself in the river (66). They begin to taunt and ridicule her as she desperately tries to connect with her father. The Lord of The Underworld then comes in and demands her to marry him. Eurydice's first action after he leaves, is to find a pen. She has made a choice and she is prepared and ready to act on it. She is accepting her reality, she is relaxing into her truth, and she is diving back into action.

She eventually finds a pen (70) and begins to write a letter to Orpheus. In the letter she sees her relationship with Orpheus objectively for, perhaps, the first time. She says, "Don't try to find me again. You would be lonely for music" (70). She is able to see this truth without falling into other pressures as she may have before. She then initiates action instructing him to find a new wife and taking it upon herself to craft a list of things for his new partner to keep in mind. She is alert, present and determined as she thinks of things, like "give him lots to eat" and "when he's sad, kiss his forward" (70). There are many items that most likely evoke an emotional response; however, the monologue is not sad, or reluctant. There is separation between thought and emotion and she fully embraces every last drop of human energy that radiates from her as she finishes this last task before turning and submerging herself in the river.

Eurydice's action of dipping herself in the river, directly after she has embraced her circumstance and traveled through the layers of willpower, represents a return to the relaxation "step." At this point, there is no escaping for her, so she might as well accept the peace that comes from the river. This was a powerful realization for me because Eurydice was not avoiding or repressing pain and grief. She was engaging with her environment to the fullest. Within my journey of building this character, expanding 
myself as a performer and growing as a person, Eurydice's choice in this moment made me realize that ultimately willpower demands going through whatever substance fills any given environment and moment; whether that substance be, a river, self-doubt, fear, exhaustion, love, excitement, dread, foreboding or frenzy.

It was only through reflection that I discovered the correlations between my journey and that of Eurydice's. The idea of applied reflection as a means for discovery and inspiration harkens back to Tami Spry and Della Pollock's articles and their ideas about the Performative-I, which are grounded in the idea of reflexivity. Reflexivity, as explored through Pollock and Spry and within the context of the Performative-I, attacks the instinctual habits of human nature to ward off vulnerable expression. It invites the onlooker to relate to the given journey in a way that strips the "I" and forms a universal "you/we." This thesis document has aimed do just that; to get inside of the journey that was my rehearsal and building process for Eurydice, in order to gain a deeper understanding of the relative impact and change of the self. On page 341 of Spry's, "Performative-I, Copresence," she talks about the process of discovery and the generation of purpose and knowledge through doing; "[...] the doing of meaning." This idea relates to many earlier discussed theories including, Meisner's “reality of doing," Polatin's "being with," and Lecoq's version of "just be." It is the act of bringing the mind to the body and the body to mind.

In her article, “The Performative-I," Pollock talks about possibilities and doing old, familiar actions in new, unpredictable ways (247). Ultimately, over the course of the Eurydice process, I used the devise of repetition to delve into the landscape of finding possibilities and options within repeated rehearsals and iterations of various parts and 
segments. I unearthed fear within creation of this nature-fear of not remembering what was done, fear of the unknown space that leads to new discoveries and fear of not knowing where to go next. Pollock addresses this sense of fear and disarms it by stating, "where there is possibility there is error" (246). To reiterate what Professor Johnny Jones said in the aforementioned interview, "[...] connection is an entrance point; a third space where binary thinking is abandoned and replaced with the desire to make discoveries." This relates to reflexive discovery because finding possibilities requires connection and "discipline of thinking and thought" (Jones) in order to release into the unknown.

In an attempt to dig out and process through the overarching, widespread realizations I have made and possibilities I discovered from the process of Eurydice, especially in regard to the ways I use willpower and connection, the following paragraphs will reflexively dive into a liminal space of exploration. This voice lies outside of the direct and explanatory tone of this document. In these paragraphs, I take the levels of thought and processing, in regard to what I learned about fear, self-doubt, ownership, presence, girlhood, expression and desire and I give myself the freedom to expound upon how they have affected me since the performances of Eurydice ended. The following pieces have been not been crafted but rather ejected onto the page- it was the process of truly allowing for immediately triggered physical reaction based on desire. There were moments while I was writing these sections that my brain would try to take over and dictate or finesse what was coming onto the page. It was only at these times that I went back. However, my method was to delete whatever had been purposefully shaped, clear my head, exhale, internally connect, and reengage with the external stimuli of the act of 
writing. Therefore, the following is an in-application example of how I have connected with the expression of physical desire through willpower and trust of myself.

Recently I traveled to New York City. Over the years I have had light to medium contact with New York. Living in Providence, I traveled there occasionally to perform or to visit friends. There has always been something about the city—-the rush of the speeding cars, the shock of the constant sounds and smells, swirling around me, filling me up, twirling me around - that simultaneously exhilarate me and leave me feeling empty, like the city took something away from me. I marvel at this phenomenon. There is an equal amount of life being drained from pour-covered skin, and life being poured into skin covered drains. The air is haunts, demands-each whip strips away as it consumes every blood vessel and cell, sweeping them into constant motion — and churns, begging my insides to survive. It is hard and brutal and harsh and all efforts to seek comfort or solace feel futile. What does not feel futile however, is gathering the life-less energylifelessness still has plenty of energy — and channeling it in a desired direction. It then becomes a beam of raw, desperate, human adrenaline: course, sharp and eager to make traction.

It is here, in this stripped away, dirty, barren state that thought seems to die and action comes alive. The body and mind respond to the conditions with an automatic efficiency. Human communication becomes effortless. Fear is on a back burner somewhere-lightly simmering, hot and ready to act should the need arise, but calm in new way-removed from the frontal lobe's real estate. Therefore, all situations can be faced and handled with no hesitation. There is a diving-in quality that emerges in a strong and palpable form. There is suddenly no room for self-doubt; survival is much 
more important than over-analyzing anything said or done. Directions are asked, jokes are made, introductions are spontaneous, new encounters become consistent. Connections are fused: to others, to a heartbeat, to the space, the air, and the heat; to pavement, the bitter breeze, the sweat, the dirt, the smoke, the garbage, the glass, the street. There is no hiding. There is no suppressing. If a mistake is made, the solution is in front of the problem, not behind.

In front lies emotion. In front lies breath. Breath brings relaxation and acceptance of my state. I do not resist or avoid or hyper-focus on emotion. I pull up a chair and sit next to it. I watch as a hot ball of wax glows brighter and expands with each rise and fall of my ribs. The ribs press against the ball and the ball presses back. Eventually, there is a smooth burst and a warm liquid oozes through the cracks. Bones swell with a burning light as disappointment, sadness, fear, loneliness, dread, longing, joy, elation, surprise, and/or frustration leisurely drizzle down to my toes and radiate up to my head. The exhales squeeze and the inhales wipe clean. I close my eyes and feel the sensations. I am interested in them; curious about them. I dive in-neutrally investigating - collecting pieces of evidence that prove my human experience. A part of me remains aware of my face; the contorted shapes of my lips and chin as the exhale sends emotion-soaked fibers out of my mouth. It's odd. The angles of my face do not match the tenor of my thoughts.

Ultimately, I have learned that the higher the stakes, the more the feeling of discouragement fades. There is simply no time. The body can only hold so many points of awareness at a given time and feeling discouraged simply becomes a waste of physical and mental energy. However, the height of the stakes does not necessarily have to come 
from external circumstances. Commitment to the moment can unveil the same level of focused and driven energy. This is accessed through reconnection to the body; connecting to one's external stimuli in order to discover response and action. The reality of doing takes hold; acting in a fully committed and authentic manner is the only option. Through courageous connection with that ball of fire inside of me, no matter how ugly or embarrassing or gross it is, the goal with my future performances as well as within my expression of my version of femininity and experience within womanhood is to connect in a way that is visceral, immediate, and fully present. Thus, engaging in a shared moment between myself and the others around me, rather than keeping my experience locked inside. In order to accomplish this goal, it will be crucial for me to face the obstacles within my own self, prohibiting my full connection, in order to "mobilize the difference between imagined and entrenched realities" (Pollock, 247), finding the bravery to step into the unknown each time I take the stage. 


\section{REFERENCES}

Agnes, Michael, ed. Webster's New World Dictionary. Gallery, 2013. Print.

Beattie, Geoffrey. Visible Thought, The New Psychology of Body Language. New York: Routledge, 2003. Print.

Brothers, Grimm. Translated by, Hunt, Margaret. Our Lady's Child. Universal Library. Date, unknown.

Gladwell, Malcolm. “The Physical Genius.” The New Yorker, 2 Aug. 1999.Web.

Graves, Robert. The Greek Myths. Vol. 1, George Braziller, 1959. The Greek Myths. Vol. 2, Penguin, 1957.

Hard, Robin, and H. J. Rose. The Routledge Handbook of Greek Mythology: Based on H.J. Rose's Handbook of Greek Mythology. Routledge, 2004.

Kelly, Baron. An Actor's Task: Engaging the Senses. Focus, an Imprint of Hackett Publishing Company, Inc., 2015.

Lamb, Sharon. The Secret Lives of Girls: What Good Girls Really Do... The Free Press/Simon \& Shuster Inc., New York, NY, 2001. Print.

Lecoq, Jacques, et al. The Moving Body: Teaching Creative Theatre. Bloomsbury 
Methuen Drama, 2014.

Magritte, René, The Lovers, 1928. Oil on canvas. MoMA, Queens, NY. Web.

McCallion, Michael. The Voice Book: for Actors, Public Speakers and Everyone Else Who Wants to Make the Most of Their Voice. Faber, 1988. Print.

Meisner, Sanford, and Dennis Longwell. Sanford Meisner on Acting. W. Ross MacDonald School Resource Services Library, 2017.

Orenstein, Peggy. Cinderella Ate My Daughter. HarperCollins Publishers. New York, NY, 2011. Print.

Polatin, Betsy. The Actor's Secret. North Atlantic Book, Berkley CA, 2013. Print.

Pollock, Della. “The Performative 'I.'” Cultural Studies Critical Methodologies, vol. 7, no. 3,2007 , print.

Smith, Anna Deavere. Letters to a Young Artist. Blackstone Anchor Books, New York, NY. 2006. Print.

Spry, Tami. “A Performative-I Copresence: Embodying the Ethnographic Turn in Performance and the Performative Turn in Ethnography." Text and Performance Quarterly, vol. 26, no. 4, 2006, print.

Rouse, W.H.D. Gods, Heroes and Men of Ancient Greece. Cambridge, UK. Mentor, 1957. Print.

Ruhl, Sarah, Eurydice. Samuel French, New York, NY, 2008. Print. 
Tharp, Twyla. The Creative Habit, Learn it and Use it for Life. New York, NY: Simon and Schuster, 2006. Print.

Wangh, Stephen, Acrobats of the Heart. Random House, Inc., New York, NY. 2000. Print

Zaslow, E.: Feminism Inc.—Coming of Age in Girl Power Media Culture. Palgrave Macmillan, New York, NY. 2009. Print. 


\section{CURRICULUM VITA}

NAME: $\quad$ Mia Donata Rocchio

ADDRESS: Department of Theatre Arts

2314 S. Floyd St.

University of Louisville

Louisville, KY 40207

DOB: $\quad$ Lebanon, NH - June 3, 1992

EDUCATION

\& TRAINING: $\quad$ BFA, Theatre Arts

University of Rhode Island

2010-2014

\section{PROFFESSIONAL EXPERIENCE:}

Graduate Teaching Assistant-September 2015-Present, University of Louisville

- Acted as the TA of Theatre 207 (Appreciation of Theatre). Duties included leading own section of class, creating lesson plans, monitoring lecture sessions, grading assignments and tests and Blackboard maintenance.

- Acted as the TA of Theatre 207, the online version. Assisted with discussion board grading, syllabus creation, aiding students with online protocol and functions, and grading tests and assignments.

- Acted as the lecturer for TA 324 (Acting for non-majors). Created syllabus and daily lesson plans. Led lectures on reading material and general course curriculum. Evaluated and graded all students and material produced (performance work, tests and essays).

Guest Teaching Artist_-November 2017, University of Louisville

- Lead a self-constructed workshop entitled, "Finding Character through Elemental Play", in which students are guided through an exploration of the 4 elements: Earth, water, fire and air. With each given substance, the students are asked to begin physically exploring as if they were that element. They begin with finding the smallest form of the given element; for example a rain drop or a spark from a match and build it to the largest; the ocean or a forest fire. After each exploration, a reflection is led in which the students create lists of personality qualities and traits, internal feelings and physical mannerisms and gestures that came up within the exploration. At the end, the lists are compared in order to gain an awareness of the contrasting energies within each element. Exploration then moves into 
improvised scenes and exercises, playing with various elements; using them as the driving energy for a given character.

Teaching Artist; Theatre Specialist - June 2017-August 2017, The Jewish Community Center, Louisville, KY

- Employed as the Dance/Drama Specialist within the Jewish Community Center's summer camp. Worked with children ages 3 to 15 . The camp was broken into teams, determined by age and led by a counselor. Over the course of one day, each group would circle through the various specialty programs for a 45 minute class. Responsible for designing curriculum specifically geared towards each age group. Themes covered for all age groups include: Character, ensemble, space, objective, relationship and story. Created lesson plans for each class; roughly taught 7 classes a day. With the story unit, guided students in the creation of a story that was then presented to the whole camp at the end of the given session.

- Other duties included assisting with the leading of morning and afternoon circle, arrival and dismissal carpool and assisting with the organization of camp-wide assemblies, talent shows and other events. Also participated in supervising overnights that took place at the JCC facility.

Teaching Artist_June 2016-August 2016, KY Shakespeare Company, Camp Shakespeare

- Employed as the lead teacher for the age group labeled, "The Groundlings". They were ages 4 through 6 . There were a total of 3 sessions for the groundlings over the course of the summer. Each session was 1 week long with a culminating performance at the end of the week. Responsible for curriculum and general layout of activities over the course of the week. Things we worked on include: making costumes, arts and crafts, yoga and mindfulness, interactive storytelling, imaginative play, improvisation, character building and pantomime.

- Also employed by KY Shakespeare as a traveling teaching artist. Required to travel outside of Louisville and teach week long camps at schools and community centers. The age range of the kids in these programs was 8-12. The curriculum and layout of these camps was similar to the structure of The Groundlings camp, accept more advanced. The final performance was based on a Shakespeare play that the kids adapted into contemporary language through the use of improvisation. They would learn the structure of the story and then get on their feet and act it out in their own words.

Creative Team Member-Sep. 2014-June 2015, Arts Alive, Barrington, RI

\section{Project one}


February-June: Created the Arts Alive Youth Workshop for young performers ages 6-8. Acted as head teacher/director/choreographer. Worked with a team of 3 other assistant teachers/directors. Designed curriculum for this 5 month program. Designed lesson plans for each weekly class. Put together final showcase that included various scenes and musical numbers from many different Broadway musicals. Choreographed and staged all vignettes. In charge of

organizing and obtaining all costumes, props and set pieces. Coordinated contracts between Arts Alive and the assistant teachers as well as with Arts Alive and the rehearsal spaces utilized for the weekly classes.

\section{Project two}

January-April: Acted as choreographer for the Spring show, Seussical the Musical. Worked with kids ages 9-12. Choreographed all dances and assisted with blocking and musical direction. Responsible for creating the parent volunteer schedule and coordinating with the PTO (parent/teacher organization) for use of the High School auditorium and rehearsal spaces.

\section{Project Three}

September-December: Co-Director/choreographer for the Fall show, Willy Wonka and the Chocolate factory. Worked with kids ages 6-8. Responsible for all choreography. Worked with other co-director to design all blocking and rehearse all songs. In charge of parent volunteer placement and schedule. In charge of costume organization and scheduling of all fittings. Assisted with set build, load-in and strike. Managed all back stage activity during performances.

Guest Artist/Mentor-March 2015-June 2015, Highlander Charter School, Warren, RI

- Employed as a theatre mentor for a 14-year old High School student interested in performing arts. Conducted weekly one-on-one sessions. Taught overview of theatre basics such as, theatre history, the various roles necessary to make a theatrical production happen, and the steps involved in perusing a professional career as a theatre artist. Coached mentee for final performance of a monologue. Assisted with and reviewed weekly journal entries submitted by mentee.

Summer Camp Instructor-June 2012-July 2012, Rhode Island College, RI

- Worked with kids ages 10-17. 7 week day-camp involving teaching improvisation workshops, musical theatre dance classes, script work and ensemble building exercises. Co-director for the one of the final productions, Alice in Wonderland, and choreographer for all group numbers in the final showcase featuring 5 different shows. Assisted with building set pieces, making costumes, and finding and building props.

Summer Camp Instructor-July 2012-August 2012, Vermont Institute of Natural Science, Queeche, VT 
- Worked with kids ages 5-7. 4 week theatre day-camp. Assisted kids with the writing of their own play. Rehearsed play and taught various theatre games. Choreographed all group dances. Helped kids build all set pieces and props. Responsible for all paper work: attendance sheets, daily parent reports and incident reports.

Teaching Assistant, Beginning Acting for Majors_January 2014-May 2014, University of Rhode Island

- Responsible for assisting in all class preparation materials including, finding and deciding on scenes for scene study work, creating syllabus (class objectives, assignment and schedule) and setting up online site for the class. Drafted daily lesson plans and in charge of all paper work - making copies of scenes, printing final lesson plans and attendance sheets and preparing any hand-outs. Led warm-ups and games. Worked one-on-one with students, coaching them through different stages of their scene work. Assisted directed final showcase presentation; took notes for the director/head teacher and helped stage blocking and transitions.

Head Teacher, Intro To Theatre for Non-Majors-September 2011-May 2014, University of Rhode Island

- Lead the acting section of the theatre course that fulfilled a general-education requirement in art. Directed a one-act play with 25 students. Gave lectures on course material, prepared and administered quizzes and exams and taught games and acting exercises in preparation for rehearsals. Responsible for guiding my assistant in terms of duties which included aiding me within the development of the show; assigned her the task of taking notes and assisting with blocking and staging.

Box Office Manager-June 2014-August 2014, Chester Theatre Company, Chester MA

- Operated as the sole Manager of all online and in person ticket sales. Responsible for producing daily deposit reports and weekly compilations of all income and ticket breakdowns. Worked with the ticketing site, Tix.com. Very familiar with Excel spreadsheets and formulas and all Microsoft Office applications. Created a pre-show slideshow using the application, imovie. This job included a large amount of costumer service both on the phone and in person. In charge of coordinating others who assisted in the production process, including, managing and overseeing the ushers and the office staff and all pre-show duties: printing program inserts, arranging the chairs and audience space, cleaning the lobby and the bathrooms and collecting tickets.

Administrative Intern-June 2013-August 2013, Wellfleet Harbor Actors Theatre, Wellfleet MA

- Duties included assisting with all daily box office tasks such as, ticket sales, on the phone and in person customer service, weekly reports, email and correspondence, and office 
organization. Planning and coordinating promotional events such as, galas, fundraisers, usher appreciation brunches, and opening night parties. Other responsibilities included, marketing and development tasks like, assisting with grant writing, website updates, postering and mailings.

House Manager-June 2013-December 2013, Wellfleet Harbor Actors Theatre, Wellfleet MA

- Acted as the sole house manager for the Summer season and returned a few times in the fall/winter season. In charge of facilitating patron organization before the show, at intermission and afterwards. Prepared all programs, pre-sale tickets and operated will-call window. Responsible for training and overseeing the ushers. Responsible for opening and running concessions booth. Counted, recorded and handled all concessions income.

\section{PRESENTATIONS:}

- Listen: A Presentation on Physical Storytelling - An examination of the ways in which physical expression on stage can be more powerful than verbal - Organization for the Study of Communication, Language and Gender Conference (OSCLG), October 2016 